\title{
HOW MUCH ROOM FOR DISCOURSE IN IMPERATIVE? THE LENS OF INTERFACE ON ENGLISH, ITALIAN AND SPANISH*
}

\author{
Mara Frascarelli, Ángel L. Jiménez-Fernández
}

Abstract. (100-150 words)

This paper discusses root phenomena in imperative clauses, assuming as diagnostics conversational dynamics and the type of discourse categories that are admitted in their Cdomain, through a systematic comparative interface investigation in three languages (English, Italian and Spanish) based on an original experimental work. This novel perspective sheds new light on the syntax-semantic mapping and the interface (syntax-prosody) properties of imperative clauses, embedding the relevant proposal in a cartographic framework of analysis. Based on a twofold distinction of root phenomena - those which are widely allowed in Common Ground-active (Type I) contexts and those which can occur in non-Common Ground-active contexts (Type II) - it is proposed that imperatives are non-Common Groundactive propositions with no update potential, thus allowing only Type II root phenomena. Syntactically, imperative clauses are dominated by a super-ordinate Speech Act Phrase, including the SPEAKER and the ADDRESSEE as co-arguments, which explains the blocking effects identified in imperatives.

\footnotetext{
"Earlier versions of this paper have been presented at the "Cambridge Comparative Syntax Meeting" (UK), the " $26^{\text {th }}$ Generative Linguistics in the Old World" in Gottingen (Germany), the $24^{\text {th }}$ "Colloquium on Generative Grammar" in Madrid (Spain) and the $1^{\text {st }}$ International Workshop on the "Interface of Information Structure and Argument Structure" in Seville (Spain). We are very grateful to the audiences there. We also thank two anonymous STUL reviewers for their precious comments and suggestions. The research here has been partially funded by research project PGC2018-093774-BI00 of Spain's Ministry of Science, Innovation, and Universities (MICINN). The order of authors is strictly alphabetical, so both of us are first authors.
} 


\section{Imperative Clauses, Root Phenomena and Information Structure: introduction and Working Hypothesis}

A number of recent works have examined the composition and extent of phrasal hierarchies of different clause types, distinguishing between root, root-like and (diverse types of) embedded clauses, and relevant phenomena (cf., among others Haegeman 2002, Meinunger 2004, Heycock 2006).

Furthermore, recent works on the interface and structural properties of discourse categories led to a clause-related distinction for different types of Topics (cf. Büring 1999, Haegeman 2004, Frascarelli 2007, Krifka 2007, Bianchi \& Frascarelli 2010, Frascarelli \& Hinterhölzl 2007, 2016, Jiménez-Fernández \& Miyagawa 2014), Foci (cf., among others, Kiss 1998, Âmbar 1999, Krifka 2007, Leonetti \& Escandell 2009, Cruschina 2011, Bianchi \& Bocci 2012, Bianchi 2013, Jiménez-Fernández 2015a,b) and Contrast, often associated with either Focus or Topic, but also as an independent feature (Vallduví \& Vilkuna 1998, Molnár 2006, Bianchi \& Bocci 2012, Frascarelli \& Ramaglia 2013, Bianchi 2013). To the best of our knowledge, however, the data examined in this respect mainly concern declarative or interrogative clauses, while no study of the so-called 'left periphery of the sentence' (cf. Rizzi 1997 and subsequent, related works) has been specifically proposed for imperative clauses.

Dislocated discourse categories such as Topics are usually associated with the presence of illocutionary assertive force, as a root property. From this perspective, imperatives are expected not to allow discourse categories that are connected with the root character of the latter. Accordingly, Haegeman (2012:64) provides the examples in (1) (see also Haegeman 2010 for additional similar examples):

(1) a. *Your essay, leave in my pigeon hole this afternoon.

b. *The weapons leave behind. 
However, the empirical puzzle emerges when we are confronted with imperatives which do permit topics in their left periphery, as in (2), also from Haegeman (2012: 64):

(2) a. The tie give to Bob, the aftershave give to Don.

(Van der Wurff 2007)

b. Anything you don't eat put back in the fridge.

(Huddleston \& Pullum 2002)

This raises the question as to what properties imperatives must satisfy in order to license or not certain types of discourse categories.

A plausible solution to this problem can be offered if we assume a distinction between different types of Topics. In this respect, Frascarelli \& Hinterhölzl (2007) propose a typology of topics based on the systematic correlation between their formal properties and their function in discourse, which is encoded in dedicated functional projections in the left periphery of the sentence. The authors thus produce substantial evidence for the existence of (at least) three types of Topics, namely Aboutness-Shift (A-)Topics, Contrastive (C-)Topics and Familiar/Given (G-)Topics (cf. $\$ 3$ below for details; see Cardinaletti 2009 and Menza 2006 for the distinction between A- and G-Topics in different constructions).

Based on this distinction, a preliminary observation can immediately lead to the conclusion that shifting (i.e. A-)Topics can hardly be associated with the imperative mood. Consider for instance (3a-b) below, from Italian: ${ }^{1}$

\footnotetext{
${ }^{1}$ The list of abbreviations and symbols used in the article is the following: $\mathrm{ALL}=$ allocutive, $\mathrm{AT}=$ Aboutness-Shift Topic, $\mathrm{CL}=$ clitic (pronoun), $\mathrm{CLLD}=$ clitic left dislocation, $\mathrm{CF}=$ Corrective Focus, $\mathrm{CG}$ $=$ Common Ground, $\mathrm{CGr}=$ Control Group, $\mathrm{CT}=$ Contrastive Topic, $\mathrm{DIR}=$ directive feature, $\mathrm{DP}=$ determiner phrase, $\mathrm{F}=$ feminine, $\mathrm{FINP}=$ Finiteness phrase, $\mathrm{F}^{0}=$ Fundamental frequency, FORCEP $=$ Force phrase, GT $=$ Given Topic, IMP $=$ imperative, IMPERS $=$ impersonal, IND $=$ indicative, IP $=$ Inflectional phrase, $\mathrm{IRR}=$ interface root restriction, JUSS $=$ jussive, $\mathrm{LD}=$ left dislocation, $\mathrm{MF}=$ Mirative Focus, $\mathrm{NEG}=$ negative, $\mathrm{PL}=$ plural, $\mathrm{PST}=$ past tense, $\mathrm{REFL}=$ reflexive, $\mathrm{SAP}=$ Speech act phrase, $\mathrm{SG}=$ singular, SUB $=$ subordinate clause, $\mathrm{SUBJ}=$ subjunctive, $\mathrm{TBU}=$ tone bearing unit, $\mathrm{TOP}=$ topicalization, $\mathrm{TP}=$ Tense phrase, $\mathrm{vP}=$ Verb phrase. The present tense is assumed as deafult and, as such, it is not indicated in the glosses.

Notice that throughout the paper, the same gloss will be provided for Italian and Spanish sentences when these are identical; otherwise, a different gloss will be given for each language.
} 
(3)a. Sono le quattro: vai subito a fare i compiti! be.3PL the four go.IMP.2SG immediately to to.do the homework 'It's four o'clock: go and do your homework immediately!'

b. *Sono le quattro: i compiti, vai subito a farli! be.3PL the four the homework go.IMP.2SG immediately to to.do-them

On the other hand, C-Topics (4B) and G-Topics (5) seem to be allowed (both in Italian and Spanish):

(4) A. Dove posso mettere questi fiori? (Italian)

¿Dónde puedo poner estas flores? (Spanish)

where can.1SG put these flowers

'Where can I put these flowers?'

b. Las rosas, ponlas en el jarrón,

the roses put.IMP.2SG-them.CL in the vase

il girasole lascialo sul tavolo. (Italian)

el girasol déjalo sobre la mesa. (Spanish)

the sunflower leave. IMP.2SG.it.CL on the table

'The roses put in the vase, the sunflower leave on the table.'

(5) [Context: A: You cannot play soccer, always keeping the ball with you...]

a. ...la palla, passala anche agli altri! (Italian)

b. ...la pelota, pásala también a los otros!

...the ball pass-IMP.2SG-it also to the others

'...pass the ball also to the others!' 
However, as translations show, English appears to provide some cross-linguistic differences. Cormany (2013) argues that non-contrastive topics are not allowed in English ${ }^{2}$ and, in general, left-peripheral arguments are often unacceptable (from Jensen 2007), as illustrated in (1) above. Nevertheless, this is not absolute. The cases considered in $(2 a-b)$ and (the translations in) (4) show that a contrastive interpretation for the topic constituents, obtain acceptable results; hence, C-Topics can be realized in English imperative clauses.

As for sentence (5), the translation shows that 'the ball' would be left in situ by speakers in this context. As a matter of fact, la palla/la pelota cannot be considered an A-Topic, because its mention is not used to introduce (or shift) the sentence Topic. Indeed, 'the ball' can be considered a background/given element in the context of a soccer game. Hence, it is a G-Topic in the framework assumed in this work and G-Topics are not dislocated in English, but rather realized through in situ destressing (as is argued in Bianchi \& Frascarelli 2010).

Similar to Topics, different types of Foci have been argued to exist in the literature, with different formal and discourse properties (cf., among others, Kiss 1998, Aboh, Hartmann \& Zimmermann 2007, Frascarelli 2010a, Cruschina 2011, Bianchi, Bocci \& Cruschina 2015). In particular, Bianchi \& Bocci 2012 argue for a syntactic and semantic distinction between Mirative and Corrective Foci and, interestingly, the realization of these two Focus types in imperative clauses also obtains different results at a first observation.

As for Mirative Focus (MF), the contrast between the declarative sentence (6a) and sentence (6b) immediately show that MF 'clashes' with the imperative mood (for reasons that

${ }^{2}$ Cormany (2013:100-101) specifically argues that in English only contrastive topics are allowed in imperative clauses, in clear contrast with declaratives (in which both contrastive and non-contrastive topics are licensed), as is illustrated in (i)-(ii):

(i) a. The book, John bought

b. *The book, buy

(ii) a. These stocks, the broker bought immediately.

b. These stocks, buy immediately! (Those avoid at all costs!)

This contrast is adduced to a relatively poor left periphery in imperative clauses (similar to Haegeman's 2004 notion of 'truncation'). As we will see in Section 5 and 6, however, a truncationbased analysis cannot account for cross-linguistic data. In addition, truncation cannot account for the grammaticality difference of examples in (1)-(2) showing that, under certain circumstances, topics can occur in the left periphery of imperatives. 
are left open here, but will be fully explained later in the paper). On the other hand, Corrective Focus (CF) looks unproblematic as long as the focused element remains in situ (7-a-a'), whereas it is unacceptable if fronted (7b'-b'):

(6) a. Sei incredibile!

be. $2 \mathrm{SG}$ incredible

Sei a dieta e... DUE PIZZE hai mangiato!

be.2SG a diet and two pizzas have.2SG eaten

'That's incredible! You are on a diet and....TWO PIZZAS we have eaten!'

b. Sei incredibile!

be. $2 \mathrm{SG}$ incredible

*Sei a dieta e.... DUE PIZZE mangia!

be.2SG a diet and two pizzas eat.IMP.2SG

(7) a. Mangia LA CARNE, non solo le patate! (Italian)

a'. ¡Cómete LA CARNE, no solo las patatas! (Spanish)

eat.IMP.2SG the meat not only the potatoes

'Eat YOUR MEAT, not only fries!'

b. *LA CARNE mangia, non solo le patate! (Italian)

b'. ${ }^{*}$ iLA CARNE cómete, no solo las patatas! (Spanish)

the meat eat.IMP.2SG not only the potatoes

The crucial characteristic that associates A-Topic and MF is that they have been argued to be strictly connected with illocutionary force. In particular, Bianchi \& Frascarelli (2010) argue that an A-Topic constitutes a speech act on its own (an 'initiating speech act', following Krifka 2001), introduced by a dedicated root operator ${ }^{3}$ and associated to the speech act

\footnotetext{
${ }^{3}$ The nature and properties of the relevant 'root operator' is not specified in Bianchi \& Frascarelli (2010). Nevertheless, considering the formal and discourse properties of an A-Topic (cf. Section 2 below), this can be identified with Krifka's (1995) Assert Operator insofar as it has the function of updating the common ground by asserting a proposition that is informative, non-contradictory and implies alternatives. As this Operator is encoded in a functional projection in the C-domain (cf. also Meinunger 2004), it is perfectly in line with the present syntax-prosody-semantic interface approach
} 
expressed by the following sentence. Along similar lines, MF has been claimed to be dependent on illocutionary force (specifically, a 'root evaluative force'), since it is a "proposal to negotiate a shared evaluation" (cf. Bianchi 2012).

Since such a connection has not been argued for the other discourse categories discussed above, we have taken this preliminary observation as our leading working hypothesis for the present investigation. Accordingly, building on the assumption that a systematic connection exists between the formal (syntax-prosody) and semantic properties of discourse categories (cf. Frascarelli \& Hinterhölzl 2007), this work takes information structure as diagnostics to provide a comprehensive explanation for the data shown above (cross-linguistic symmetries and discrepancies), define the root/non-root quality of imperatives and provide a structural analysis (in a cartographic perspective; cf. Rizzi 1997) which can account for the discoursesemantic properties of imperatives. ${ }^{4}$

More precisely, the present working hypothesis can be formulated as follows: if root phenomena like A-Topic and MF cannot be hosted in imperative clauses, this can be taken as evidence that the latter are not endowed with illocutionary force. Consequently, according to the types of discourse categories that are allowed, an information-structural characterization will be proposed, which can also account for their semantic properties.

To this purpose, a comparative interface investigation is proposed, dealing with the acceptability of A-Topics, C-Topics, G-Topics, MF and CF in English, Italian and Spanish imperative clauses. The analysis is based on judgments collected by means of an original online survey, and recordings of the relevant sentences (cf. Section 4.4. below for details). In addition, we complement the online rating test with a prosodic analysis of the different discourse categories. Based on a ToBI characterization (Pierrehumbert 1980) of the intonational contours associated to the sentences used for the online survey, the present

study.

${ }^{4}$ The existence of a systematic correlation between the discourse and formal (syntax-prosody) properties of different types of Topics, put forth in Frascarelli \& Hinterhölzl (2007) for Italian and German, has been checked and assumed in a number of works on typologically diverse languages like Somali (Puglielli \& Frascarelli 2009), Tagalog (Frascarelli 2010b), English (Bianchi \& Frascarelli 2010), Spanish (Jiménez-Fernández 2016), Finnish and Russian (Frascarelli 2018), Old English (van Gelderen 2013), and Icelandic (Sigurdsson 2011). Based on this cross-linguistic validation, it is taken as a working hypothesis for the present analysis. 
interface study will check what type of intonation the informants associate to the discourse categories that they have judged as acceptable in the written test. This will be crucial to understand whether they assigned the intended interpretation or, rather, their acceptance is based on a (maybe collaborative) misinterpretation of the relevant discourse function - a risk that cannot be avoided in written tests, especially in languages like Italian and Spanish, in which all Topic types are realized through CLLD constructions while all Focus types are never clitic-resumed.

Our work is organized as follows. In section 2 we discuss the 'Root/non-root distinction' and illustrate the notion of 'Root phenomena' providing several examples for the relevant distinction in different languages. In section 3 we present the discourse categories addressed in the present investigation and address their role with respect to Conversational Dynamics. Section 4 provides a short survey on the major properties of imperative clauses, focusing on their mixed (root/non-root) character. In section 5 the interface analysis is presented: informants' judgments are analyzed and confronted with the relevant prosodic realizations in the three languages under examination (English, Italian and Spanish).

Based on the evidence collected, a novel proposal on the syntactic mapping of imperatives is put forth in Section 6, capitalizing on Farkas \& Bruce's (2010) approach to conversational dynamics and examining the imperative structure in the light of the update potential of the discourse categories allowed in the relevant left periphery. Imperatives will be thus characterized as non-Common Ground active propositions, as we will see below.

This means that, even though imperatives affect the context by issuing a directive act, this counts as an instruction, not as a piece of information. Notice that, in this respect, we follow Krifka (2007) and assume two dimensions for the Common Ground (CG) Management, distinguishing between (i) Conversational Moves and (ii) Instructions, where only the former can modify the CG Content. Therefore, to say that imperatives are instructions amounts to claiming that their conversational import implies an update of the Addressee's TO-DO-LIST, while it does not count as an update of the interlocutor's CG Content. In other words, 'nothing is added to the CG' (cf. also Roberts 2018), even though imperatives can have access to it (see Lauer 2013 for a framework in which information is updated with information about utterance events).

In the cartographic approach that we assume to account for interpretive levels, this means that the assertive feature in ForceP is inactive and, as a consequence, all the projections 
connected with its activation (e.g., the projections hosting the A-Topic and the MF) are not available. To explain the imperative interpretation, it will be proposed that this is connected with a Modality projection, activated (through Agree) with a directive feature encoded in C. Finally, in order to account for the participants involved in this type of directive act, the imperative proposition will be argued to be selected as the object of a Speech Act Phrase including the ADDRESSEE and the SPEAKER as co-arguments.

Section 7 is dedicated to a specific interface restriction concerning low-toned (G-Topic) constituents in imperatives and Section 8 offers our final conclusions.

\section{The Root/Non-root Distinction}

\subsection{What is a Root clause?}

To provide a clear-cut, uncontroversial definition of a 'root clause' is far from trivial. Since Emonds (1970, 1976), this quality has been attributed to clausal domains which could only host some types of phenomena (like Left Dislocation) and the relevant 'root restriction' has been connected to the availability of what can be defined as assertive force (cf. Bianchi \& Frascarelli 2010) in these clauses. Hooper \& Thompson (1973) make the point that this restriction only relies on semantic/pragmatic requirements and cannot be accounted for syntactically. ${ }^{5}$ In this sense, assertion is connected with illocutionary force:

As a positive environment we can say that [root] transformations operate only on Ss that are asserted. [...] some transformations are sensitive to more than just syntactic configurations. It does not seem possible to define the domain of an RT in terms of syntactic structures in any general way. However, [...], even if it were possible to define in syntactic terms the conditions under which RTs can apply, [...] the question of why these transformations can apply in certain syntactic environments and not others would still be unanswered (Hooper \& Thompson 1973:495).

\footnotetext{
${ }^{5}$ In this respect Hooper \& Thompson (1973) only state that the assertion of a sentence is 'its core meaning or main proposition', which 'may be identified as the part that can be negated or questioned'. Sentences, however, may contain more than one assertion (e.g. coordination) and, crucially, some subordinate clauses are asserted (cf. Section 2.2).
} 
This claim is supported by the observation that 'root transformations' are actually also allowed in syntactically embedded clauses whose content constitutes the main assertion:

(8) It appears [that this book he read thoroughly]. (Hooper \& Thompson 1973: 478)

This challenge was then taken up by different authors in the generative framework, who tried to elaborate a syntactic account for the relevant restriction. ${ }^{6}$ Emonds $(1970,1976)$ observed that for many speakers dependent clause contexts mimic the freedom of root structures in indirect discourse. However, root-like indirect discourse embedding is incompatible with most dependent clause positions (cf. Emonds 2004).

A syntactic approach to root transformations was also adopted by Liliane Haegeman in a number of works, mainly focusing on adverbial clauses (e.g. 2006, 2010, 2012). Specifically, Haegeman's (2006) first approach to the root/non-root issue strictly relies on a cartographic difference concerning the extension of the relevant C-domains (i.e., the functional projections composing the left periphery): root phenomena depend on the activation of ForceP, which is missing in the left periphery of non-root clauses. Nevertheless, in later works the author herself pointed out the limits of such an approach, showing that the presence of illocutionary force per se is not a sufficient condition for root phenomena to apply. Hageman $(2010,2012)$ then argues that the incompatibility between root phenomena and some clausal environments depends on an intervention effect between the operator movement that is required by a given clausal type and the operation involved by the relevant root transformation. ${ }^{7}$ Presupposed

\footnotetext{
${ }^{6}$ Several works and proposals have been also elaborated by scholars operating in non-generative, nonformal approaches, in which the restrictions on the use of particular constructions are sought in functional properties, whether cognitive, processing or discourse-functional, while leaving the basic structure of the construction for formalist analysis. In particular, for a semantic and discoursepragmatic approach to root phenomena (often referred to using different terms), the interested reader is referred to McCawley (1977); Kuno \& Kaburaki (1977), Kuno (1987), Prince (1981), Birner (1995), Verstraete (2005), Hengeveld \& Mckenzie (2008), Ward, Birner \& Kaiser (2017), among many others.

${ }^{7}$ Intervention effects have been originally explored in formal syntax in connection with weak-island phenomena (cf. Szabolcsi 2005 for an overview). For the purposes of the present analysis, we follow Rizzi's $(2004,2018)$ account and assume a Relativized Minimality (RM) version of the intervention principle, according to which:
} 
environments, for instance, are factive in nature, and factives have been argued to involve operator movement (cf, among many others Watanabe, 1993).

In a similar vein, Haegeman \& Ürögdi (2010), Jiménez-Fernández \& Miyagawa (2014) and Jiménez-Fernández (2018) propose that non-root clauses contain an operator which prevents some discourse categories from moving to the C-domain. For Jiménez-Fernández \& Miyagawa (2014), some types of topics can move in non-root clauses because movement targets a position within the sentential (IP)-domain, after inheritance of the discourse feature by $\mathrm{T}$ (ense) from C(omp). Moreover, Jiménez-Fernández (2018) argues that Negative Preposing (a phenomenon that Emonds (1970) considers as restricted to root contexts) is possible in non-root sentences in Spanish because it targets TP and not CP, thereby avoiding any intervention effect (see also Jiménez-Fernández 2020).

(i) In the configuration $[\ldots \mathrm{X} \ldots \mathrm{Z} \ldots \mathrm{Y} \ldots]$ a local relation connecting $\mathrm{X}$ and $\mathrm{Y}$ is disrupted when there is a $\mathrm{Z}$ such that:

A) $\mathrm{Z}$ is of the same structural type as $\mathrm{X}$, and

B) $\mathrm{Z}$ intervenes between $\mathrm{X}$ and $\mathrm{Y}$

A proper comprehension of this model thus requires a definition of what counts as an 'intervener'. For the sake of space, we can briefly state that this notion implies that:

(a) the intervening element must intervene hierarchically, not just linearly;

(b) the class of interveners is featurally selective.

Characterization (a) explains why from a baseline sentence like (iia) extraction of the temporal adjunct when is ill formed (cf. (iib), whereas from a baseline like (iiia) movement of when is possible, as in (iiib):

(ii) a. Leo asked who you will arrive at five

b. *When [did Bill ask [ who [ will arrive ]]]]

(iii) a. The doubt about who passed the exam ended at five

b. When [ did [ the doubt [ about [ who passed the exam ]]] end ]?

On the other hand, characterization (b) explains why quantificational adverbials like beaucoup ('a lot') in French intervene in combien extraction (cf. iva), whereas manner adverbials like attentivement ('carefully') do not (cf. Laenzlinger 1998):

(iv) a. * Combien a-t-il beaucoup consulté [ de livres] ?

'How many has he a lot consulted of books?'

(v) a. Combien a-t-il attentivement consulté [ de livres]?

'How many has he carefully consult of books?' 
From a different, multi-layered perspective, Bianchi \& Frascarelli (2010:19) suggest that the restriction imposed on some phenomena to be realized in clausal domains (potentially) endowed with assertive force complies with plausible interface requirements and can be easily accounted for within the tradition of update semantics (cf. Farkas and Bruce 2010). This means that syntactic restrictions might not be the cause, but the consequence of specific interpretive requirements at the interface levels (i.e., phonetic and logical form). In other words, it is plausible to assume that, for their prosodic and illocutionary properties, certain clausal types do not allow specific syntactic operations because the relevant output could not be interpreted (it would 'crash') at the interfaces (on the application of this approach to adverbial clauses, cf. Frascarelli 2019).

This is the approach assumed in this paper for the root/non-root dichotomy, that is to say, a dynamic view of semantic interpretation, whereby the meaning of a sentence is its update potential: a function from an input context to an output context. The input context is the set of possible worlds that are compatible with the conversational $\mathrm{CG}$, i.e. the set of propositions that are taken to be presupposed, up to that point, by all the participants in the conversation. The updating effect of an assertion is that the asserted proposition, when accepted by all the participants, is admitted into the CG, and thus discards from the input context all the possible worlds that are incompatible with it (technically, by intersection), yielding a 'shrunken' output context. (cf. Bianchi \& Frascarelli 2010 for discussion and Section 6.1. for additional details).

From this perspective a root clause is a clausal domain endowed with update potential and root phenomena are phenomena that can only be hosted in CG-active propositions, that is to say, assertive acts whose propositional content modifies (and updates) the CG.

\subsection{Two types of root phenomena}

Root phenomena are primarily instances of movement to the left periphery of the clause (cf., among others, Hooper \& Thompson 1973, Heycock 2006). These include operations like VP preposing (9a), Negative constituent preposing (9b), Topicalisation (9c), Left Dislocation (9d), Locative inversion (9e), Preposing around 'be' (9f) and Subject auxiliary inversion (9g), in English. However, the best studied root phenomenon, namely V2 constructions, is not from 
English (as is shown for German in (10) below; on V2 phenomena see, among others, Gärtner 2002, Wiklund, Bentzen, Hrafnbjargarson \& Hróarsdóttir 2009):

(9) a. Mary plans for John to marry her, and marry her he will.

b. Never in my life have I seen such a mess!

c. This novel you should read.

d. This book, it has the recipe in it.

e. On the wall hangs a portrait of the David Bowie.

f. Standing next to me was the Dean of the Department.

g. Will James ever finish reading that book?

$\begin{array}{cllll}\text { (10)Dieses } & \text { Buch wollte } & \text { ich } & \text { gestern } & \text { lesen. } \\ \text { this } & \text { book } & \text { want-PST.1SG I } & \text { yesterday } & \text { read }\end{array}$

'Yesterday I wanted to read this book.'

Based on distributional properties and scope interaction, Bianchi \& Frascarelli (2012) provide evidence for a distinction across left-peripheral root phenomena. Specifically, the authors identify and discuss two types of root phenomena:

(i) Type I root phenomena like Left Dislocation (11) and Focus Fronting in Italian (12), which can occur in root clauses and in complements of bridge verbs (e.g., say, think), ${ }^{8}$ but cannot occur under emotive and factive predicates (e.g., be glad/sorry, regret, resent), or under volitional verbs (e.g., hope, wish, would like),

(ii) Type II root phenomena like English Topicalization (13) and V2 constructions, which can occur in root clauses and in complements to bridge verbs, but also in complements to volitional verbs (wünschen 'wish'+SUBJ-II, hoffen 'hope'+IND; cf. Meinunger 2004: 316),

\footnotetext{
${ }^{8}$ The 'bridge' term traditionally refers to verb allowing for long-distance dependencies (i.e., verbs of saying and opinion, like say and think, whose complement clauses do not form a 'barrier' for movement). In investigations dedicated to root phenomena, complements of bridge verbs play a major role since they have a 'quasi-root' character, that is to say, they allow for the realization of root operations, while this is not possible in complements of factive or volitional verbs (cf., among others Bianchi \& Frascarelli 2010, Gärtner 2001, Haegeman 2002, Emonds 2004, Meinunger 2004, Heycock 2006).
} 
both with a Focus (14) and a Contrastive Topic (15) interpretation as is shown in the following examples (examples from Bianchi \& Frascarelli 2012):

(11)a. *I am glad [that this unrewarding job, she has finally decided to give it up].

b. *I hope [that the past he will forget it soon], so as to bravely face the future.

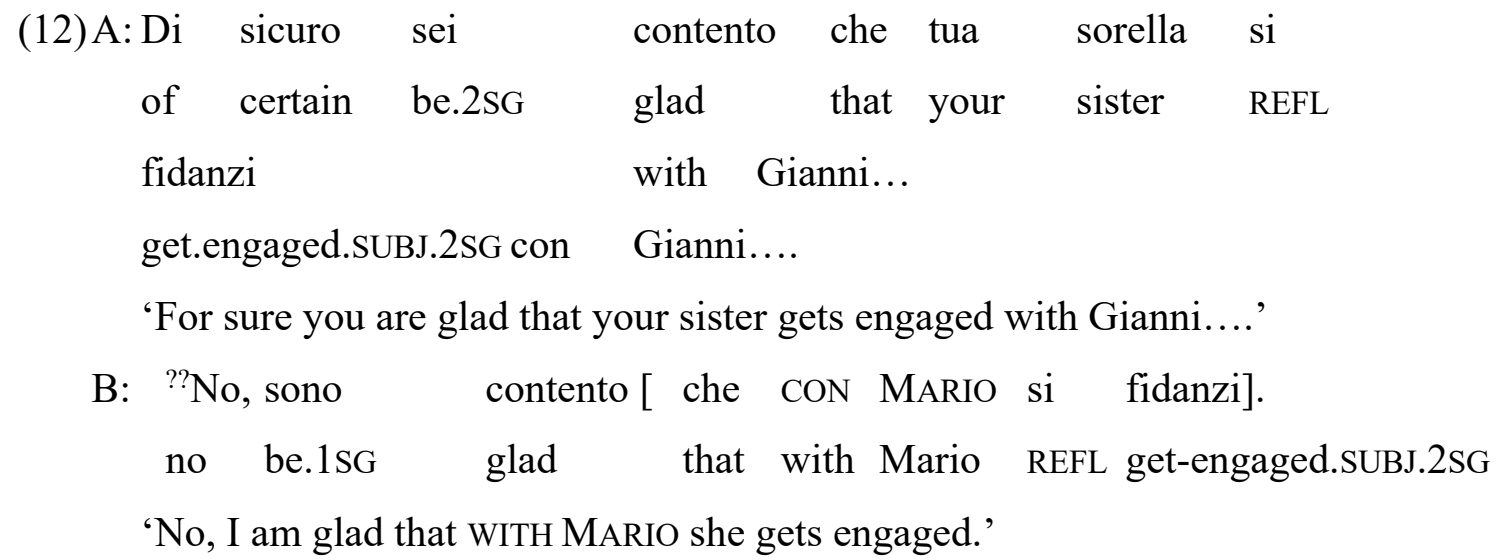

(13)I hope that the past he will forget _, and the future he will face _ bravely

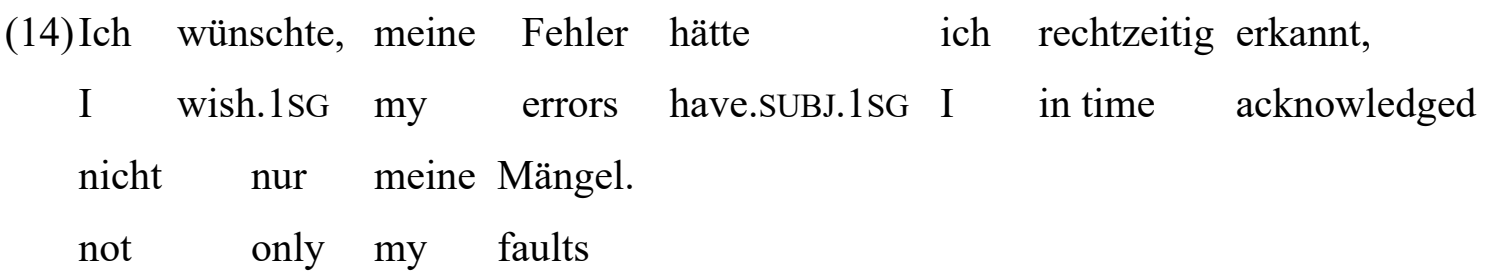

'I wish I had acknowledged my errors in time, not only my faults.'
(15)Ich wünschte, meine Fehler hätte ich rechtzeitig erkannt I wish.1SG my errors have.SUBJ.1SG I in time acknowledged und meine Wünsche realisiert. and my wishes realised

'I wish I had acknowledged my errors in time and realised my wishes.'

As will be clear later, the distinction between the two types of root phenomena will play a crucial role in the study and understanding of imperative clauses. 


\section{Discourse Categories and Conversational dynamics}

Based on Frascarelli \& Hinterhölzl's (2007) typology, Bianchi \& Frascarelli (2010) show that discourse categories have different functions in conversational dynamics insofar as they have different roles in the CG management. More precisely, they provide evidence that a discourse category that triggers an update of the discourse context can only occur in clauses endowed with context update potential. Supported by comparative data, this observation leads the authors to formulate the Interface Root Restriction (16).

(16)Interface Root Restriction (IRR, Bianchi \& Frascarelli 2010, (8))

Information Structure phenomena that affect the conversational dynamics (CG management) must occur in clauses endowed with illocutionary force that implement a conversational move. ${ }^{9}$

Consistent with the present approach, we refine the IRR and argue that Type I root phenomena can only occur in CG-active clauses, which have an impact on the shared components of the discourse structure and aim at updating the CG. Consequently, when a Type I root phenomenon occurs in a complement clause, the latter must be interpreted as (potentially) CG-active. In other words, the CG-active quality is not restricted to root clauses, but extends to some 'root-like' clauses (cf. also the notion of 'quasi-subordinate' in Dayal \& Grimshaw 2009 and 'main point of utterance' in Simons 2007). On the other hand, Type II root phenomena (C-Topics) can also occur in non-CG-active clauses (or a subset thereof), as they are not linked to the CG-oriented conversational dynamics.

Since imperatives are argued not to be CG-active, this hypothesis predicts that Type I root phenomena are disallowed in imperative clauses, whereas they are allowed in

\footnotetext{
${ }^{9}$ Following Krifka (2007), two dimensions of the CG are assumed, namely the CG content and the CG management. The CG content is the truth-conditional information accumulated up to a given point in the conversation. The CG management includes (i) the sequence of conversational moves requiring illocutionary force, and (ii) the instructions that help the interlocutor determine the way in which the CG content develops and is organized (not independent conversational moves per se).
} 
propositions expressing assertive force. These include both main declaratives and questions ${ }^{10}$ (both connected with illocutionary force; cf. Hooper \& Thompson and relevant discussion in Section 2.1).

This approach allows for an uncontroversial classification of those root phenomena that show apparent inconsistencies across languages (e.g., they can occur in some subordinate clauses and, vice versa, some root contexts do not allow the presence of some of them), since it links them to illocutionary force, depending on their update potential. An overview on the formal and discourse properties of the categories to be treated is therefore in order and provided in the next section.

\subsection{The Aboutness-shift (A-)Topic}

The A-Topic connects Reinhart's (1982) aboutness ('what the sentence is about') with the property of being newly introduced or reintroduced to propose a shift in discourse. Assuming with Reinhart that the CG is not an unordered set of propositions, but is divided into subsets of propositions ('file cards') that are stored under defining entries, the A-Topic can be defined as the entry identifying the file card under which the proposition expressed in the sentence is stored. Consider for instance the following passage (from the naturalistic corpus used in Frascarelli 2007), in which the speaker is talking about 'Romans' games' but, after a while, she decides to shift to 'Romans' social life', which becomes the 'storing entry' for the subsequent assertion (topics will occur in bold type in the examples throughout the paper):

10 Though questions are traditionally considered different from assertions insofar as they are interrogative statements (and, as such, interpreted in a specific functional projections in the Cdomain), we follow a recent proposal, fully discussed in Krifka (2015), according to which questions should be considered as (a type of) assertions.

To make this proposal as simple as possible, we can summarize his argumentation saying that in Krifka's semantic framework questions are analysed as a derivative of assertions. Specifically, Krifka's article develops a theory of conversational update that does not only model the current common ground (called 'commitment state'), but also its projected continuation (the 'commitment space'). This leads to a new conception of questions as conversational moves in which the speaker suggests particular assertions by the addressee. 
(17)Nell' antica Roma i giochi avvenivano sempre durante la giornata [...] in.the ancient Rome the games occur.PST.3PL always during the day 'Games always occur during the daytime in ancient Rome [...]' In realtà la vita dei romani avveniva sempre durante il giorno. in reality the life of.the romans occur.PST.3SG always during the daytime 'Actually, the social life of Romans would always take place during the daytime.'

According to Krifka (2001: 25), topic selection is a speech act itself. Specifically, it is 'an initiating speech act that requires a subsequent speech act, like an assertion, question, command, or curse about the entity that was selected'. This means that the A-Topic complies with a conversational move and, as such, this operation is restricted to CG-active propositions. Given our working hypothesis, this means that the A-Topic qualifies as a Type I root phenomenon.

This discourse-semantic qualification is supported by distributional and scopal properties, since A-Topics are only allowed and interpreted in clauses in which the Assert Operator is active (cf. note 3). Hence, a Topic shift cannot be proposed in complements to factive verbs (cf. (18)) and a shifting topic cannot be in the scope of matrix clause negation (19) or a matrix QP (20): ${ }^{11}$

(18) A: Hai saputo? Mario verrà questa sera alla festa. E' così simpatico!

'Did you know? Mario will come to the party this evening. He's so nice!'

B: Sì! *Ma mi
yes but to.me mind.3sG that his sister not her see.1SG
da tempo

\footnotetext{
${ }^{11}$ Supporting evidence is given by the fact that both 'sua sorella' in (18) and 'tutti i suoi parenti' in (19) are fully accepted if located in the left periphery of the relevant matrix sentences, as expected. It should be also noticed that the left-dislocated existential QP in the embedded clause in (20) cannot be interpreted in the scope of the matrix clause, both in Italian and with English LD (in the translation).
} 
(19)A: Leo torna a casa dopo tanto tempo all'estero e vorrei organizzare una cena per lui, ma temo che inviterà tutti i suoi parenti....

'Leo is coming back home after a long time abroad and I'd like to organize a dinner for him, but I'm afraid he will invite all his relatives...'

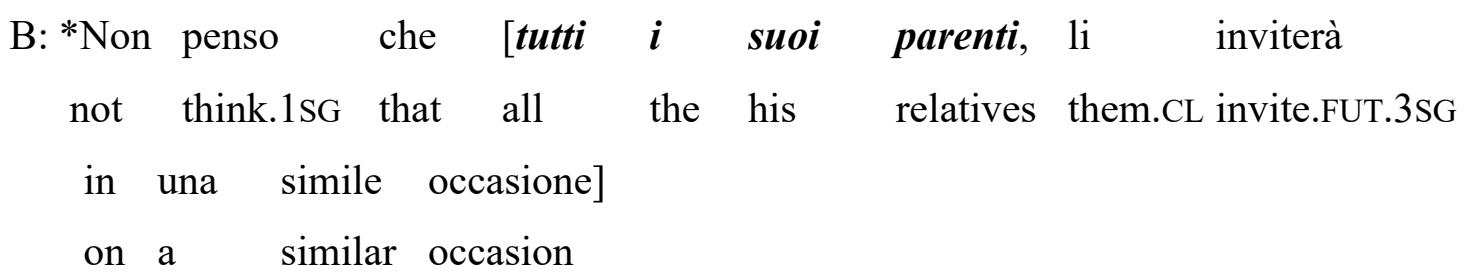

(20) Ogni mio amico mi ha detto [che un esame, lo posso preparare in due settimane] 'Every friend of mine told me [that one exam, I can prepare it in two weeks].' (* $\forall>\exists)$

As for its cartographic representation, in all the languages examined so far (cf. note 4), the A-Topic formally qualifies as the topic located in the highest topic position in the left periphery and associated with the complex $\mathrm{L}^{*}+\mathrm{H}$ tone. According to the ToBI notation (Pierrehumbert 1980), this means that the topic shift is signalled by a rise in the $\mathrm{F}^{0}$ contour that is aligned with the tonic vowel in its full extension, while the highest point is reached on the post-tonic vowel (cf. Gili-Fivela et al. 2015).

\subsection{The Contrastive (C-)Topic}

C-Topics induce alternatives in the discourse that have no impact on the Focus value of the sentence. Specifically, in the Alternative Semantics approach (cf. Rooth 1992, Beaver \& Clark 2008) it is argued that a contrastive Focus generates a set of alternative propositions (varying in the position of the focused element), while C-Topics imply a set of questions hierarchically ordered by entailment relations. In particular, Büring (2003) argues that to obtain congruence every declarative clause containing a C-Topic must be the answer to a question belonging to a set of alternatives (either explicit or implicit) questions, which are all 
part of a strategy to solve a super-question. In other words, Büring's C-Topic provides an instruction for the hearer on how to relate the asserted proposition to a strategy of inquiry. ${ }^{12}$

In this line of analysis, Bianchi \& Frascarelli (2010:72) suggest that the C-Topic marking is used to 'break down a complex proposition into a conjunction of simpler ones in which a predicate applies separately to each member of a salient set'. This is illustrated in the Italian dialogue below:

$\begin{array}{rlllll}\text { (21)A: Dove } & \text { stanno } & \mathrm{i} & \text { tuoi fratelli } & \text { adesso? } \\ \text { where } & \text { stay.3PL } & \text { the } & \text { your } & \text { siblings } & \text { now }\end{array}$

'Where are your siblings now?'

$\begin{array}{lccccc}\text { B: Carlo è a } & \text { casa come } & \text { sempre, } & \\ \text { Carlo be.3SG at } & \text { house as } & \text { always } & \\ \text { Mario non lo } & \text { vedo } & \text { da una } & \text { settimana. } \\ \text { Mario not him.CL } & \text { see.1SG } & \text { for one } & \text { week }\end{array}$

'Carlo is at home as usual, Mario, I haven't seen for a week.'

C-Topics thus provide an instruction to the speaker and, as such, they do not constitute in themselves independent conversational moves. This means that, unlike A-Topics, C-Topics are not restricted to CG-active domains, though they cannot be hosted in a clause that is less than a proposition (i.e., properties or event modifiers). We thus conclude that C-Topics qualify as Type II root phenomena.

This discourse-semantic qualification can be proved showing that C-Topics are allowed in complements to factive verbs (cf. (22)) and in the scope of a matrix QP (23), contrary to ATopics (as is shown for Topicalization in English in (13) above):

(22) Sono contenta che Mario venga alla festa, però mi dispiace [che suo fratello, non voglia venire e che sua sorella, non l'abbiano nemmeno invitata]

\footnotetext{
${ }^{12}$ This means that a sentence like $[\text { Fred }]_{\text {Ст }}$ ate $[\text { THE BEANS }]_{\mathrm{F}}$ is part of a "discourse-tree" entailing the super-question Who ate what? and the relevant sub-questions (\{What did Fred eat?, What did Mary eat $?, \ldots\})$.
} 
'I'm glad that Mario will come to the party but I'm sorry that [his brother doesn't want to come, and his sister, they have not invited]'.

(23) Ogni mio amico mi ha detto [che un esame, lo posso preparare in due settimane e un concorso, lo posso preparare in due mesi] $(\forall>\exists)$

'Every friend of mine told me [that one exam, you can prepare in two weeks, and a competition, you can prepare in two months].'

Syntactically, the C-Topic is located in a position in the left periphery that is lower than the position hosting the A-Topic whereas, prosodically, it is characterized by a high tone that is aligned on the tonic vowel $\left(\mathrm{H}^{*}\right)$, which is realized as a complex tone $\left(\mathrm{L}+\mathrm{H}^{*}\right)$ in a number of languages (the so-called 'B-Accent', cf. Büring 2003).

\subsection{The Familiar/Given (G-)Topic}

G-Topics refer to given information that is somehow salient to the conversation. Since givenness is calculated on the basis of the $\mathrm{CG}$ content, it can be said that the main function of a G-Topic is the retrieval of given information that is stored in the CG repository. This retrieval can be operated either via 'strongly given' constituents in the discourse (i.e., definites triggering an identificational presupposition; cf. Heim 1982), or through 'familiar' discourse referents that are (i) perceptually accessible in the utterance, (ii) globally familiar from shared cultural knowledge, (iii) contextually entailed to exist, or (iv) implied via 'bridging'13 (cf. Roberts 2003). An illustration of the distinction between a strongly given Topic (24) and a familiar G-Topic (25) is provided in the following dialogues (from Frascarelli \& Hinterhölzl 2016):

\footnotetext{
13 'Bridging' inferences refer to the resolution of indirect anaphoric relationships between entities in a text or a discourse, to be drawn by recipients in order to make sense of the linguistic input, which often does not fully specify the intended meaning of utterances. In this process, contextual knowledge plays a crucial role for a successful interpretation of the intended meaning of specific texts and discourses.
} 
(24)A: Adoro il pollo, perché si mangia con le mani. adore.1SG the chicken because IMPERS eat.3SG with the hands 'I love chicken, because you can eat it with your hands'

B: Anch' io! Anche se il pollo non lo mangio molto spesso. also I even if the chicken not it.CL eat.1SG very often 'Me too! Even if I don't very often eat chicken.'

(25)A: Adoro il cibo che si mangia con le mani. adore.1SG the food that IMPERS eat.3SG with the hands 'I love that (kind of) food that can be eaten with your hands'

B: Anch' io! Anche se il pollo non lo mangio molto spesso. also I even if the chicken not it.CL eat.1SG very often 'Me too! Even if I don't very often eat chicken.'

The retrieval function of G-Topics can serve either (a) to ensure topic continuity, that is to say, to maintain the current A-Topic through one or more low-toned copies in the topic chain created by the A-Topic itself; this is the function of the so-called Aboutness G-Topic; or (b) to mention a constituent that is part of the background, but it is not a copy of the current A-Topic and, importantly, it is not proposed for a topic shift (this is defined as Background G-Topic; for discussion, cf. Frascarelli 2017, 2018, and Frascarelli \& JiménezFernández 2019).

Consider for instance the following passage and, in particular, the sentence underlined at the end:

(26)I gladiatori $\mathbf{k}_{\mathbf{k}}$ [A-Topic] entravano nell'arena sfilavano, salutavano gli spettatori e salutavano soprattutto l'imperatore, poi si recavano davanti alla tribuna [...] e c'era l'arena, che era praticamente un tavolato di legno sul quale veniva buttata della sabbia $\underline{\mathrm{e}}$ su questa (Background G-Topic), loro $\underline{\mathbf{k}}_{\text {, i gladiatori }} \mathbf{k}$ (Aboutness G-Topics) lottavano.

'The gladiators would enter the arena, (they) marched, (they) greeted the public, and (they) hailed the emperor first of all, then (they) used to go in front of the gallery [...] and 
there was the arena, which was practically a wooden stage covered with sand and on this they - the gladiators - would fight'

As is clear, the underlined pronoun loro and the DP $i$ gladiatori are used to resume (and maintain) the current A-Topic, introduced at the beginning of this passage and heading a long chain of null subjects (cf. Frascarelli 2007, 2017; for similar cases in Spanish, see also Jiménez-Fernández 2016). Hence, they are part of the current topic chain and qualify as Aboutness G-Topics. On the other hand, the left-dislocated PP su questa refers to 'the arena': an entity that is part of the background and was previously introduced in the text. However, its mention is not intended for a Topic shift: the following discourse keeps on talking about the gladiators. The arena thus qualifies as a Background G-Topic. ${ }^{14}$

Syntactically, the G-Topic is merged in the lowest Topic position in the left periphery and its tonic vowel is realized as a low tone at the minimum of the speaker's range, with no significant difference in comparison with the pretonic $\mathrm{F}^{0}$ level (i.e., as a $\mathrm{L}^{*}$ tone). Contrary to A- and C-Topics, G-Topics can be multiple and can appear in the right periphery of the sentence (always assuming Merge in the left periphery and deriving its final position through IP-inversion; for details, cf. Frascarelli 2000, Cardinaletti 2002).

Since in our system givenness is calculated on the basis of the CG content, G-Topics clearly do not instantiate a conversational move and do not depend on illocutionary force. This implies that the G-Topic can be hosted in non CG-active propositions. Consider, for instance, the Spanish example (27), in which a G-Topic is realized within a central adverbial clause (from Jiménez-Fernández \& Miyagawa 2014:298), which is argued not to be endowed with illocutionary force (cf. Haegeman 2002 and subsequent, related work):

\footnotetext{
${ }^{14}$ Unfortunately, the limitations imposed by a written text do not allow the illustration of the prosodic contours and space restrictions impose a short exposition of the relevant contexts. In the absence of intonational cues, it is therefore important to remember that the crucial distinction between A- and GTopics rests on the shifting function of A-Topics (whereas they share the 'aboutness' quality). Hence, in (26) the PP su questa is undoubtedly a G-Topic because the conversation does not shift to 'the arena': the speaker keeps on talking about loro (i.e., 'the gladiators', which is the current A-Topic). Mutatis mutandis, la vita dei romani in (17) above cannot be a G-Topic because the conversation shifts to that discourse topic after its introduction. See Frascarelli \& Jiménez-Fernández (2019) for further refinements on the role of G-Topics in topic continuity.
} 
(27) Julia no ha entregado la tesis en el departamento porque Julia not have.3SG submitted the thesis in the department because el capítulo final no lo ha terminado todavía. the chapter final not it.CL have.3SG finished yet 'Julia has not submitted her thesis to the Department because she has not finished her final chapter yet.'

\subsection{The Mirative Focus (MF)}

Brunetti (2009) and Cruschina (2011) consider Mirative Focus (MF) as not purely 'informative'. Specifically, in Bianchi (2013), Bianchi et al. (2015) and Jiménez-Fernández (2015b), it is argued that MF provides new information and, based on the speaker's knowledge of the hearer's expectations, it signals that such information will be unexpected. Usually, this unexpectedness is an indication of the speaker's surprise with respect to the fact that is being described. Consider the Italian example below (here and in the following examples small caps are used to indicate Focus):

$$
\begin{array}{rlllll}
\text { (28) Non ci } & \text { posso credere! } & \text { DUE } & \text { BOTTIGLIE ci siamo bevuti! } \\
\text { not in.it } & \text { can.1SG believe.INF } & \text { two } & \text { bottles } & \text { REFL be.1PL drunk }
\end{array}
$$

'I can't believe it! Two BOTTLES we drank!'

In contrast with Information Focus, Bianchi $(2013,2015)$ underlines that MF does not depend on a question-answer context. Therefore, in a sentence like (28) the focused constituent does not satisfy any request in any possible question. Rather, a contrast is established with an element that is part of the CG repository of the participants and can be semantically described as a 'proposal to negotiate a shared evaluation with the hearer(s)' (Bianchi 2015: 64).

Concentrating on this characterization, MF qualifies as a Type I root phenomenon since it depends on illocutionary force and implements a conversational move. From an intonational point of view, a fronted MF is characterized by a $\mathrm{H}^{*}$ tone (cf. Bianchi et al. 2015, Frascarelli \& Ramaglia 2013). 


\subsection{The Corrective Focus (CF)}

Differently from Contrastive Focus (with which it is often confused), the Corrective Focus $(\mathrm{CF})$ is not just the rejection of a (question-answer) congruent alternative in a given set. Rather, a CF conveys an incompatible description of one and the same event (cf. van Leusen 2004, Bianchi \& Bocci 2016). Specifically, using Bianchi \& Bocci’s (2012:6) words:

"There is one alternative proposition, already introduced in the context, which is incompatible with the proposition expressed in the corrective reply. The incompatibility import implies that accepting both the antecedent proposition and the corrective claim would lead to an inconsistency: this is what gives rise to the correction effect, whereby speaker A's assertion is rejected by speaker B."

Syntactically, a CF can be realized both fronted (in a position that is generally defined as higher than the G-Topic, but lower than A- and C-Topics) and in situ, as is shown in the following example:

(29)A: I heard you met Fred yesterday.

B: No, BILL I met / No, I met BILL'

Given this characterization, CF clearly qualifies as a conversational move and, as such, it requires to be hosted in a CG-active proposition. Hence it is a Type I root phenomenon. Phonologically, a fronted CF is cross-linguistically marked by a pitch reaching high values, which is preceded by a low tone $\mathrm{L}+\mathrm{H}^{*}$ (Bianchi et al. 2015). As for the in situ realization, different prosodic characterizations can be found in the literature. Specifically, taking elicited sentences as a basis, Bianchi et al. (2015) argue for a $\mathrm{L}+\mathrm{H}^{*}$ realization (exactly as in the fronted option), while Frascarelli \& Ramaglia's (2013) study provides evidence that an in situ $\mathrm{CF}$ is not pitched, but integrated in the downgrading contour of the sentential Intonational Phrase. 


\section{Major Properties of Imperative Clauses: a Brief Survey}

In this section we briefly present the main traits suggested in the literature to describe imperatives. It is needless to say that we cannot make justice to all the studies that have concentrated on the syntax and semantics of these constructions, especially when the goal of our work is to explore the information structure of imperatives and the consequences for the multi-faceted analysis that we propose.

\subsection{Negation and tense}

From a morphological viewpoint, there is no general consensus on the finite/non-finite quality of the relevant verb form; hence, a clear-cut characterization can be hardly assessed. In some cases the imperative form is expressed by means of some kind of finite verbal form, which is specifically identified as such across languages. This is the case of two of the three languages under examination here, namely Spanish (30) and Italian (31):

\begin{tabular}{|c|c|c|}
\hline $\begin{array}{l}\text { (30) Ven } \\
\text { come.IMP.2SG }\end{array}$ & $\begin{array}{l}\text { pronto! } \\
\text { soon }\end{array}$ & \\
\hline 'Come soon!' & & \\
\hline (31) Aspetta & un & attimo! \\
\hline wait.IMP.2SG & $\mathrm{a}$ & minute \\
\hline
\end{tabular}

On the other hand, some languages seem to use the base form (English) or the participle (Dutch, classical Hebrew). However, the imperative can also be expressed through a finite form, namely the subjunctive, in languages like Greek and French (and partially in Spanish and Italian as well). This variety has opened a vivid discussion among scholars concerning the inflectional status of the imperative form, which cannot be treated in detail in the present paper. Nevertheless, since the root/non-root distinction is a major topic in the present analysis 
and the internal structure of imperatives will be addressed in our proposal, some further discussion is needed.

In this respect, we consider as crucial the evidence provided by negative imperatives. In particular, Zanuttini (1996) convincingly shows that the realization of sentential negation in imperatives correlates with the inflectional form of the verb, Tense playing a relevant role (cf. also Rivero \& Terzi 1995, Zanuttini 1996, 1997, Zeijlstra 2006). Specifically, Zanuttini (1996: 188) argues that a ban on 'true' negative imperatives is imposed in languages like Italian and Spanish simply because in the split-IP hierarchy the functional projection in which Negation is encoded (NegP) selects TP (i.e., the head of NegP takes TP as its complement) and imperatives lack TP, but not agreement. For this reason, the imperative form (32a) cannot be used in the presence of negation, and a suppletive form emerges (32b). On the other hand, it can be used with the forms that are identical to the indicative (33a-b). Similarly, Spanish does not allow the presence of the negative head no with second person imperatives (34a-b) and expresses the negative imperative using the subjunctive (35a-b), extracted from Zanuttini (1996:188-189):

(32)a. Cammina! walk.IMP.2SG

'Walk!' b. *non cammina! / non camminare!

not walk.IMP.2SG not walk.INF

'Don't walk!

$\begin{array}{lllll}\text { (33)a. Non camminate! } & \text { b. } & \text { Non camminiamo sopra 1' erba. } \\ \text { not walk.IMP.2PL } & & \text { not walk.IMP.1PL on the grass } \\ \text { 'Don't walk (2PL)!' } & & \text { 'Let's not walk on the grass.' }\end{array}$

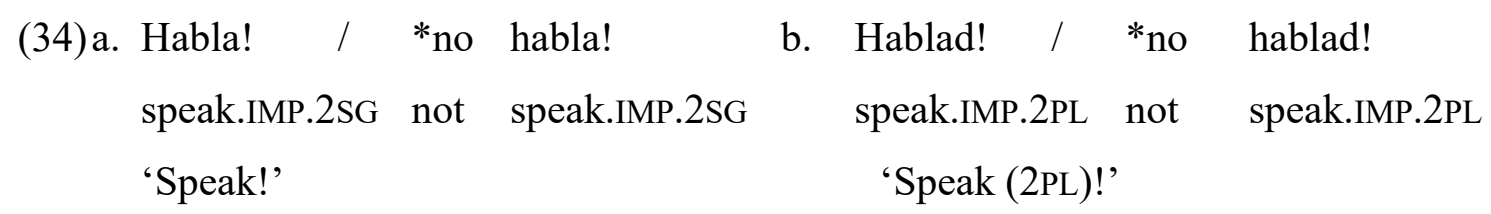
(35)a. No hables!
b. No habléis!
not speak.SUBJ.2SG
not speak.SUBJ.2PL
'Don't speak!'
'Don't speak (2PL)!' 
We assume Zanuttini's analysis and therefore consider the imperative as a finite defective form, lacking TP, but featuring both Mood and some form of agreement in the I-domain. This assumption will be supported by the present analysis and discussed in the structural proposal later. In other words, we assume that the IP of true imperatives (those with morphological forms unique to imperatives; cf Rivero 1994) is only endowed with agreement features. This is supported by the incompatibility of negation and true imperatives, assuming that NegP selects TP in these languages (as is argued in Zanuttini 1996; cf. above). ${ }^{15}$

With respect to the syntactic properties, one of the main concerns in the analysis of imperatives is whether they exhibit root or non-root properties, since, though superficially independent, some evidence supports their 'embedded' qualification. As a matter of fact, imperatives show subordinate-like morpho-syntactic properties in languages like Latin. Considering negation once more, for instance, imperative verbs require a subordinate negative marker (cf. Evans 2007): ${ }^{16}$

${ }^{15}$ However, one problem that is posed by the lack of $\mathrm{T}$ is that temporal adverbs such as now and later are fully compatible with true imperatives, as shown in (i):
(i) Hazlo
ahora/después.
(ii) *Hazlo antes.
do.IMP.2SG-it now/later
do.IMP.2SG-it before
'Do it now/later.'
'*Do it before.'

This compatibility points to the possibility that some sort of Tense is present in imperatives. A plausible solution can be assuming the Split TP system proposed by Sigurdsson (2016), according to which the T-system is divided into three dedicated projections, namely Utterance Time, Reference Time and Event time. Provided that the temporal adverbs allowed here are connected with the utterance time, there may be an Utterance Time Phrase in imperatives, whereas other T projections are not realized (indeed, (ii) above shows that a Reference Time projection should be missing).

16 The parameters of negation in Latin have been argued to display a complex pattern of interdependencies, the illustration of which is totally beyond the purposes of this paper. For an overview of this question and relevant references the interested reader is referred to Gianollo (2016). 
(36)a. Venias!

come.SUBJ.2SG

'Come!'/ 'May you come!'

b. Non / *ne venias!

$\operatorname{not}(\mathrm{SUB}) \quad \operatorname{not}(\mathrm{ROOT}) \quad$ come.SUBJ.2SG

'May you not come!'

The present investigation is intended to shed light on this issue, focusing on the properties of imperatives' left periphery.

\subsection{Anaphoric relations, subjects and topics}

If Tense is generally assumed to be lacking in imperatives, a major question concerns agreement and the realization of subjects. Actually, true imperatives show $2^{\text {nd }}$ person agreement, independently of the overt 'subject' possibly preceding the verb. This is also clear in anaphoric relations, which do not 'work' as in standard (root) clauses, as is illustrated in (37), where a $2^{\text {nd }}$ person anaphoric possessive is the standard form used to refer to the $3^{\text {rd }}$ person 'subject' everybody, even though 'their' is also accepted and its use is becoming rather common: ${ }^{17}$

(37) Everybody raise your ('their/*?his) hand!

${ }^{17}$ 2nd person agreement also emerges in tag questions (cf. (i)), which are generally assumed to be a root phenomenon. Nevertheless, Bianchi \& Frascarelli (2010) have shown that tag questions can also occur in complements of verbs of saying and opinion, hence in 'quasi-root' contexts (iia-b). This means that tag questions qualify as a Type II root phenomenon, according to the finer distinction adopted in the present analysis:

(i) Wash yourself, won't you?

(ii) a. I think (that) you like it, don't you?

b. Mary believes that Lucy is pregnant, isn't she? 
The observation of (anti)agreement phenomena in imperatives has led authors to different explanations. Among the most influential, Downing (1969) and Ross (1970) propose that imperatives are embedded within a higher performative predicate and that the interpretation of the imperative subject is determined by an argument in the superordinate clause, which can be null because of an operation of deletion. ${ }^{18}$

Refuting the performative analysis, authors in the GB framework have tried a characterization of the imperative subject as an empty category. In this respect, Potsdam (1988) defends the position that the English imperative has a largely unexceptional syntax and argues that no special particles nor ad hoc rules need to be assumed for the various manifestations of the syntactic imperative, which can be accounted for in terms of familiar clause structural properties (I-to-C movement, do-support, Case as a form of spec-head agreement, and so on). As for the subject, a vocative analysis is strongly excluded: the imperative subject is located in its canonical Spec,IP and, when it is not overt, it is a pro. Surprisingly, Postdam does not linger on this final claim which - leaving aside the merits of his work - meets an immediate problem with the exceptionality of such an empty category in non pro-drop languages. Beukema \& Coopmans (1989) also claim that imperative clauses can be given a 'fairly orthodox syntactic representation'; however, they do not consider a pro analysis and suggest that the imperative subject is a variable bound by a possibly null element in a topic position. Another possibility proposed in the literature is that the imperative subject is a PRO (Han 2000:115-160): since imperatives can pattern either with subjunctives or with non-finite forms, Han concludes that the subject is overt when the imperative patterns with a subjunctive, while the subject operator must be a PRO with infinitive forms. Though the picture might appear neat and tidy, problems arise with Case assignment and Control, since the imperative subject position seems to be case-marked and it is also not clear what element could control the imperative subject PRO. More recently in the Minimalist framework, Zanuttini (2008) posits the existence of a Jussive head in the I-domain, containing an interpretable $2^{\text {nd }}$ person feature, which semantically binds the subject and licenses it (through

\footnotetext{
${ }^{18}$ This proposal will be re-elaborated in the present structural analysis.
} 
an Agree relation). 'True agreement' and the existence of a subject position in imperatives will be also addressed in this paper (cf. Section 7). ${ }^{19}$

For the purpose of the present investigation, it is finally important to notice that imperatives clearly allow for some type of Topic in Italian and Spanish, as illustrated in the following examples:

(38)a. La camicia, stirala!

the shirt iron.IMP.2SG-it.CL

b. ¡La camisa plánchala ya!

the shirt iron.IMP.2SG-it.CL right now

${ }^{19}$ As for the realization of subjects in imperatives, notice incidentally that in V2 languages like Dutch and German the imperative verb occupies a pre-subject position, as is shown in (ia) below for Dutch and (ib) for the German polite formula ('Hoflichkeitsform'), and that this position is also possible in Italian (ii) and Spanish (iii):

(i) a. Trek jij maar je jas aan.

'Pull you but your jacket on.'

b. Kommen Sie.

'Come you.'

(ii) Metti tu la giacca $(=($ ia $))$

(iii) Ponte tú la chaqueta $\quad(=($ ia $))$

However, the realization of a postverbal overt subject pronoun in Italian imperative clauses seems to be connected with some discourse-related intention - possibly a Contrastive Focus interpretation:

(iv) Metti TU la giacca, non tuo fratello (che non ha mai freddo)!

'YOU must put your jacket on, not your brother (who is never cold)!'

On the other hand, preverbal subjects in imperatives are rather closer to Contrastive Topics:

(v) Tu, metti la giacca; tuo fratello, metterà un cappotto.

'You - put your jacket on, you brother will wear a coat.'

We keep these observations (to be tested with informants) for future research. 
'Iron the shirt!'

Nevertheless, Clitic Left Dislocation (CLLD) in Romance languages is compatible with both root and non-root contexts (Bianchi \& Frascarelli 2010, Haegeman 2012, JiménezFernández \& Miyagawa 2014), but CLLD can implement different types of Topics, with different requirements with respect to illocutionary force (cf. Section 3). Hence, an investigation on the acceptability of specific discourse categories in imperative clauses is necessary to understand the root/non-root character of fronted constituents. ${ }^{20}$

As for English Topicalization, there is no general consensus on its acceptability in imperatives, as is illustrated by apparent contrasts like the one - given above in (1) and (2), provided in Haegeman (2012: 64) - and repeated here as (39) and (40):

(39)a. *Your essay, leave in my pigeon hole this afternoon.

b. *The weapons leave behind.

(40)a. The tie give to Bob, the aftershave give to Don. (Van der Wurff 2007)

b. Anything you don't eat put back in the fridge. (Huddleston \& Pullum 2002)

However, if Frascarelli \& Hinterhölzl's (2007) typology is adopted, the relevant grammaticality contrast is clarified: examples such as (40a-b) represent instances of C-Topics, whereas this reading is not contextually entailed in (39a-b). As a matter of fact, the idea that contrastiveness can enable topics to show up in contexts where they otherwise do not occur has been stated by different authors (cf. Prince 1998, Portner \& Yabushita 1998, Büring 2003, Meinunger 2004). The relevance of Frascarelli \& Hinterhölzl's proposal rests on the systematic connection between the contrastive discourse function and a specific formal (syntax-prosody) realization in the C-domain. Hence, a finer discourse analysis proves to be crucial to understand and solve apparent inconsistencies.

\footnotetext{
${ }^{20}$ As a matter of fact, we can see that sentences like (38a-b) are grammatical in Italian and Spanish; however, in the absence of intonational and discourse cues, we cannot know what type of topic (i.e., A-, C- or G-Topic) is implemented by la camicia/la camisa 'the shirt'.
} 


\subsection{Mapping the imperative meaning in syntax}

The syntax-semantic mapping of imperative clauses represents a complex and controversial issue in the literature and different proposals have been put forth to explain how the imperative meaning is syntactically encoded (i.e., relevant projections and dedicated features).

Several authors have proposed that the relevant mapping depends on a clause-typing operation; in this type of approach, the imperative is encoded as a Force feature in the split$\mathrm{CP}$ domain that composes the left periphery (also called C-domain). In particular, according to Han (2000), imperatives have an illocutionary operator with directive force, which is represented in the syntax via two specific features (i.e., [directive] and [irrealis]) encoded in $\mathrm{C}^{\circ}$. Schwager (2006), on the other hand, argues that imperatives have a performative modal of universal force in Spec,CP, whose head carries a [+imp] feature triggering V-to-C movement. ${ }^{21}$ Movement operations are a crucial device to license the 'imperative force' also in Koopman (2007), in which clause-typing is enforced by moving FinP to Spec,ForceP. On the contrary, Cormany (2013) proposes that in imperatives V raises to Fin and the subject to Spec,FinP, so that the imperative force does not drive movement per se.

Against a clause-typing analysis, some authors have argued that the $\mathrm{C}$-domain has no role in the relevant mapping. Portner (2004) holds that there is nothing specific to imperatives, rather a pragmatic operation forces the Addressee to add an instruction to his/her To-Do-LIST and Jensen (2007) claims that imperatives lack a CP domain altogether (a position that is difficult to maintain, given the availability of Topics in the left periphery).

Finally, Zanuttini (2008) and Zanuttini, Pak \& Portner (2012) put forth the idea that the imperative meaning is encoded in a clause-specific projection, namely the Jussive Phrase (JussP). This projection plays a role in "preventing the instantiation of a predication relation between the subject and the predicate" (2008:185). Zanuttini's proposal is very attractive since it combines a Minimalist analysis (in terms of Agree) with Ross' (1970) Performative

\footnotetext{
${ }^{21}$ Notice that the existence of a V-to-C movement was already defended in the GB framework by authors like Potsdam (1988). Rivero and Terzi (1995), for instance, explain the emergence of a surrogate form in negative imperatives in the light of a block operated by NegP on verb movement to the C-domain.
} 
Hypothesis. Ross' seminal intuition will be also important for our proposal, though recasting the performative hypothesis as a level of abstraction that capitalizes on the relevance of discourse analysis and the root/non-root distinction.

The availability of a Jussive head in imperatives plays a crucial role in distinguishing the position occupied by the verb in the three languages under exam. We will suggest that the syntax will differ when English and Italian/Spanish data are confronted since the verb position in Spanish and Italian seems to be higher than in English (see Section 6.2 below).

\section{The analysis of data}

\subsection{What about discourse? Diagnostics and methodology for the analysis}

All approaches to imperatives illustrated in Section 4 have focused on their morpho-syntactic and semantic properties. This raises two major questions:

1) Depending on their root/non-root character, what limitations (if any) can be found for discourse-related categories in imperatives?

2) Depending on independent core grammar properties, is there any cross-linguistic variation in the type of discourse categories permitted in the imperative C-domain?

In order to answer these two major questions and provide an interface-based syntactic mapping of imperative clauses, a questionnaire has been built up for a systematic comparative analysis concerning the acceptability and interpretation of different discourse categories (ATopics, C-Topics, G-Topics, CF and MF) in imperative clauses, in the three languages under examination (English, Italian and Spanish).

The relevant test was composed of 24 target sentences divided in 5 groups (each dedicated to a specific discourse category), and 6 fillers. ${ }^{22}$ Target sentences were either

\footnotetext{
${ }^{22}$ Though it is generally suggested (as a 'rule of thumb') to use as many fillers as the number of target sentences, we preferred not to overload informants with too long a questionnaire to avoid the risk it could be left uncompleted. Indeed, fillers are particularly important to divert informants' attention, concealing the intended objective of the analysis. However, this is not an issue for the present experiment, in which informants were asked to provide acceptability (not grammatical) judgments on target sentences. Furthermore, the test was 'inherently diversified' given that different discourse
} 
proposed in the form of a dialogue or preceded by an appropriate context for the intended reading of the dislocated constituent. ${ }^{23}$ Target sentences were randomized and fillers were introduced at regular intervals. Informants were thus asked to provide a judgment on the acceptability of 24 sentences containing either a dislocated or a fronted constituent (underlined in the relevant dialogues), using a Likert scale from 0 to $4 .{ }^{24}$ The results obtained with the Likert scale have been then confronted considering their median values and, finally, statistically analysed through the parametric techniques of ANOVA (Analysis of Variance).

The questionnaire was provided as an online survey, with open access, thus collecting 274 full questionnaires for Italian, 95 for Spanish and 82 for English. The survey was

categories were examined (hence target sentences included different types of both Focus and Topic constructions).

${ }^{23}$ The syntactic properties of dislocated/fronted constituents have been properly controlled: the discourse categories tested are always located in the left periphery of the relevant matrix clause and connected with the DO function in the local clause. Consequently, all types of Topics are resumed by a clitic in CLLD languages (Spanish and Italian), whereas resumption is excluded in the case of Foci (in all languages) and for C-Topics in English (since Topicalization is applied).

As for prosodic factors, the prosodic phrasing of the target sentences has been systematically checked across the three languages, in order to secure the syntactic hypothesis, in particular: (a) the dislocated/fronted constituent is always the only discourse category realized in the relevant left periphery, and (b) the imperative verb never marks the right boundary of the sentential intonational phrase, so as to avoid the possible interference with boundary tones.

The syllable weight of words could not be always kept constant, since we wanted to maintain a perfect parallelism of meaning for every set of examples in the three languages. Nevertheless, target words in Spanish and Italian are mostly paroxytones (with two exceptions) and English words are mostly monosyllabic. At any rate, results are very consistent across examples and no differences emerged related to prosodic weight, hence this factor appears to be immaterial for the phenomenon under discussion.

${ }^{24}$ A Likert scale is a particular type of scale, proposed in Likert (1932), to measure the informants' attitude towards a specific (set of) statement(s). Likert scales prototypically measure agreement and are composed of 5 (or 7) agreement grades (from ' 0 ' for 'strongly disagree' to ' 5 ' for 'strongly agree'). 
anonymized, ${ }^{25}$ but preceded by a socio-demographic section allowing for the characterization of the informants: aged from 20 to 55 , both male (55\%) and female (45\%), 95\% resident in their own countries, 90\% with high education (Bachelor and Master degree). Furthermore, almost $50 \%$ declared to have proficiency in a second language and $30 \%$ declared to have some training in linguistics.

Online respondents' judgments were confronted with those of a Control Group composed of 10 native speakers, monolingual, with high education and no training in a foreign language or in linguistics. The function of this Control Group (CGr) is to check whether native informants with no (or limited) contacts with speakers of a different language and no training in a foreign language or in linguistics (hence, with no 'pre-conceptions' about structures and theories) could have different judgments on the relevant structures. As it will be shown in the Tables below, however, these judgments are generally in line with the rest of informants (whose characteristics were totally mixed), thus showing that results do not depend on sociolinguistic and/or demographic factors.

In a second step of the analysis, a selected number of respondents collaborated in the recording of the 24 sentences used for the online test (excluding the fillers), in order to check whether specific intonational contours are systematically associated to the different discourse categories under exam. For these productions we selected 4 informants ( 1 male and 3 female) whose mean evaluation on all conditions was higher than 1, coming from Rome, London and Seville, respectively, for the Italian, English and Spanish test and ranging from the age 20 to 30 , with university level education. Recordings have been made in a quiet room at the Centro Linguistico (CLA) of Roma Tre and at the Laboratorio de Fonética of Seville. The speakers have been asked to read silently the contexts preceding the target sentences (underlined in the text) and only read aloud the latter. Hence, the corpus includes 16 realizations for each discourse category ( 4 target sentences produced by 4 informants), in the 3 languages examined.

\footnotetext{
${ }^{25}$ Nevertheless, since a prosodic analysis was also prospected for this study, this 'second step' was announced in the instructions and an email account was provided, encouraging informants to contact the authors in case they were interested in a further collaboration.
} 


\subsection{Acceptance and interface realization of discourse categories in imperative clauses}

In the following sub-sections the results obtained for each discourse categories will be confronted for the three languages under examination. Acceptance rates are then commented and followed by the illustration of relevant intonational contours, supporting and/or motivating the conclusions that have been drawn from the observation of the Likert scale median values. The analysis of variance will then follow in a separate Section (5.3).

\subsubsection{A-Topics in imperative clauses}

Table 1 below reports the median value ${ }^{26}$ of the judgments expressed on the 5 target sentences used to evaluate the acceptability of A-Topics in imperative clauses. As is shown, values are consistently low across languages:

Table 1. A-Topics in imperatives

\begin{tabular}{|l|l||l|l||l|l|}
$|l||l||l|$ & \multicolumn{2}{l|}{ Italian } & \multicolumn{2}{l|}{ Spanish } \\
\hline Informants & CGr & Informants & CGr & Informants & CGr \\
1.20 & 1.81 & 1.09 & 0.84 & 1.79 & 1.61
\end{tabular}

Based on these judgments, we can conclude that the A-Topic - a discourse category implementing a conversational move and requiring assertive illocutionary force - is hardly (to say the least) accepted in imperative clauses.

Furthermore, the prosodic realization of these dislocated constituents in the relevant sentences has shown that acceptance was in fact connected to a different Information Structural (IS) interpretation. Specifically, instead of the expected $\mathrm{L}^{*}+\mathrm{H}$ raising contour, the 'intended' A-Topics are produced in the majority of cases (44 out of 48), for all languages,

\footnotetext{
${ }^{26}$ In statistics and probability theory, a median is the number separating the higher half of a data sample, or a probability distribution, from the lower half. It is the most resistant statistic, having a breakdown point of $50 \%$. A median is only defined on ordered one-dimensional data, and is independent of any distance metric dimensions (cf. Baayen 2008).
} 
with a $\mathrm{H}+\mathrm{L}$ sequence, which we analysed as a bi-tonal pitch accent $\mathrm{H}^{*}+\mathrm{L}$ in 40 cases, since it is phonetically realized as a rise to a peak around the middle of the syllable, in the first half of the tonic vowel, and a fall that reaches the end in the TBU (cf. the description in Gili Fivela et al. 2015:148), as is shown in Figures 1-2 below (the target sentence analysed in these and the following Figures is underlined in the relevant example). Notice that, for the sake of space, we will generally provide the English version (and Figure), followed by either the Italian or the Spanish equivalents: ${ }^{27}$

(41) a. If you read now, you won't listen to me.

The book, leave it on the table and come here for a second!

Figure 1. Intended A-Topic in English imperatives

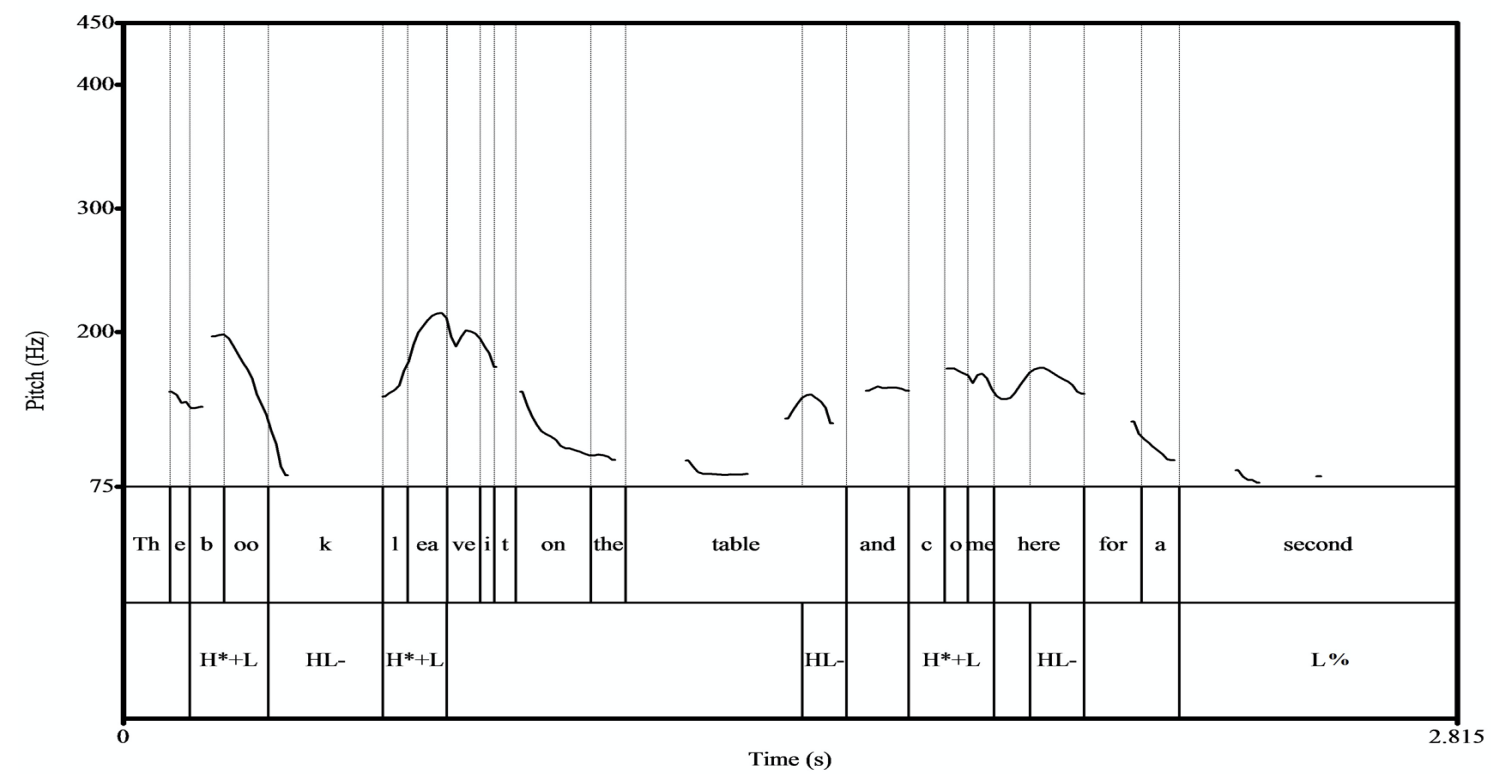

$\begin{array}{rlllll}\text { (41)b. Se leggi } & \text { adesso } & \text { non } & \text { puoi } & \text { ascoltarmi. } \\ \text { if } & \text { read.2SG } & \text { now } & \text { not } & \text { can. 2SG } & \text { hear.INF-me.CL }\end{array}$

${ }^{27}$ In this section English Left Dislocation and Topicalization are confronted with CLLD Topic constructions in Italian and Spanish. We are fully aware that these constructions have different formal and interpretive properties (for discussion, cf. Cinque 1900, Gregory \& Michaelis 2001, among many others): their comparison is solely based on their classification as Type II root phenomena, discussed in Section 3 above. 
'If you read now, you can't hear me.'
Il libro, lascialo
sul tavolo e vieni
qui un attimo!
the book leave.IMP.2SG-it.CL on.the table and come. IMP.2SG here a moment
'The book, leave it one the table and come here for a moment!'

Figure 2. Intended A-Topic in Italian imperatives

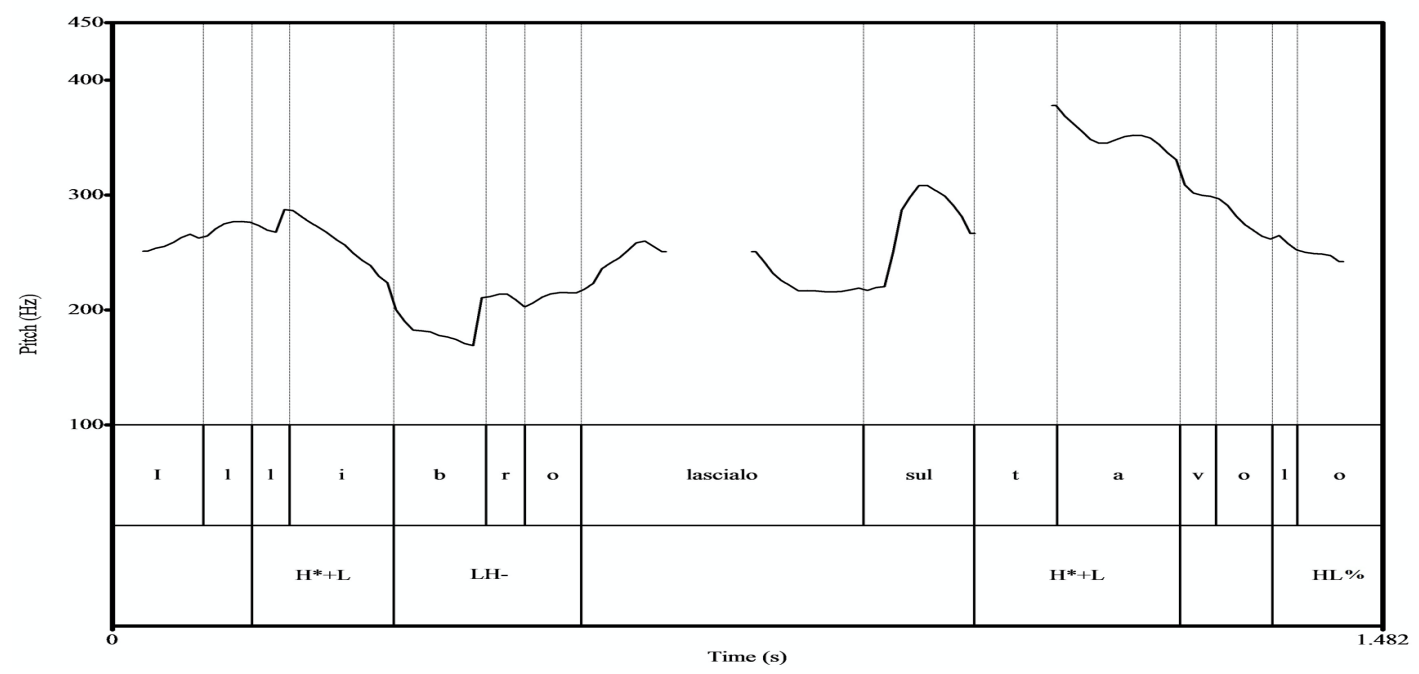

It should be noticed that the same pitch accent is associated with the predicate in the subsequent imperative clauses. This is interesting since $\mathrm{H}^{*}+\mathrm{L}$ is commonly defined as the typical contour of directive acts (cf., among others, Pierrehumbert \& Hirschberg $1990^{28}$ and Esteban \& Prieto 2010) and this consideration makes it plausible to suggest that the (intended) A-Topic was in fact 'reinterpreted' by informants as a sort of 'covert imperative', that is to say, a 'verbless directive act' that is conjoined with (or juxtaposed to) the following imperative clause. Additional support to this working hypothesis is provided by the fact that these dislocated constituents never form an independent Intonational Phrase (as is instead the case of A-Topics, cf. Frascarelli \& Hinterhölzl 2007, Frascarelli \& Carella 2019): their

\footnotetext{
${ }^{28}$ According to Pierrehumbert \& Hirschberg (1990: 297), "the H+L accents [...] are used by [the speaker] to evoke a particular relationship between the accented items and [the hearer]'s mutual beliefs." Importantly, $\mathrm{H}^{*}+\mathrm{L}$ differs from $\mathrm{H}^{*}$ "in the conveying that the hearer should locate an inference path supporting the predication."
} 
prosodic realization is marked by an Intermediate Phrase boundary, which can be either low (cf. $\mathrm{HL}^{-}$in Figure 1) or high (cf. $\mathrm{LH}^{-}$in Figure 2) across language. Though interesting, this hypothesis is beyond the purposes of this investigation and is therefore left for future research.

For the purposes of the present analysis, the fact that the intended A-Topic actually corresponds to a different discourse category leads to the conclusion that proposing or shifting "what the sentence is about" is not an available function in the C-domain of imperative clauses. Since the A-Topic has been argued to be a Type I root phenomenon (Bianchi \& Frascarelli 2010), the present result suggests that imperative clauses are not endowed with context update potential.

\subsubsection{MF in imperative clauses.}

Data concerning the acceptability of MF yield immediate and consistent evidence that this kind of discourse category, connected to the speaker's evaluation and dependent on illocutionary force, cannot be realized in imperative clauses. As is shown by the median values in Table 2 below, a sentence like (42) below is undisputedly rejected by informants. Consequently, no prosodic elicitation was carried out for the sentences dedicated to MF in the online questionnaire.

Table 2. MF in imperatives

\begin{tabular}{|l|l||l|l||l|l|}
$|l||l||l|$ & \multicolumn{2}{l|}{ Italian } & \multicolumn{2}{l|}{ Spanish } \\
\hline Informants & CGr & Informants & CGr & Informants & CGr \\
0.12 & 0 & 0.59 & 1.02 & 0.33 & 0.23
\end{tabular}

(42)a. *I can't believe it! TWO BOTTLES drink!

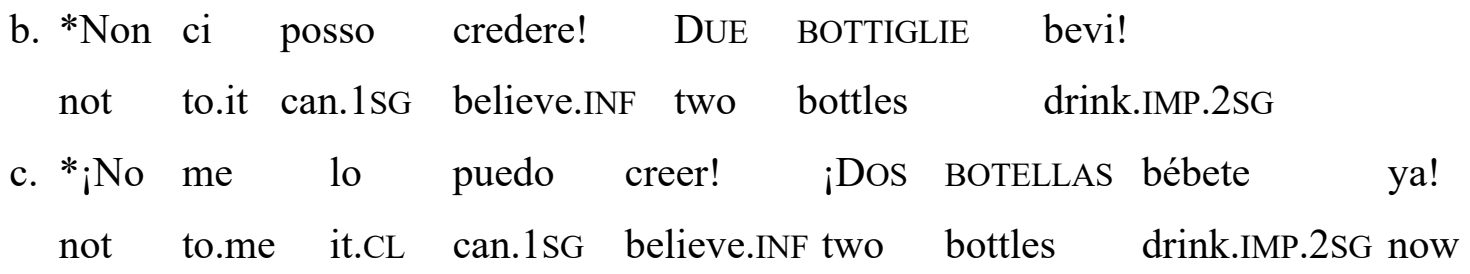


This result strongly supports the conclusion that imperatives cannot host MF. Based on the characterization provided above (cf. §3.4), we can conclude that a discourse category that implies a conversational move, that is to say a request for evaluation on something apparently in contrast with shared knowledge (assumed to be stored in the CG), cannot be realized in an imperative clause. Hence, the latter is not a CG-active proposition and MF confirms its qualification as a Root I phenomenon.

\subsubsection{CF in imperative clauses.}

Judgments on the acceptability of CF in imperative clauses show an interesting asymmetry between in situ and fronted realization: while a fronted CF (43) is rejected by informants (with values comparable to those attested for MF; cf. Table 2 above), an in situ CF (44) is fully accepted in the three languages examined. Let us then confront Tables 3 and 4, showing the two realizations of the same sample sentence:

(43)a. A: Can I have a glass of wine, please?

B: You must drive after the party: WATER have instead, not wine!

b. A: Posso avere un bicchiere di vino perfavore? can.1SG have.INF a glass of wine please

'Can I have a glass of wine, please?'

B Devi guidare dopo la festa.

must.2SG drive.INF after the party

ACQUA bevi piuttosto, non vino!

water drink.IMP.2SG rather not wine

'You must drive after the party, WATER have instead, not wine!'

Table 3. Fronted CF in imperatives

\begin{tabular}{|l|l||l|l||l|l|}
$|l||l||l|$ & \multicolumn{2}{|l|}{ Italian } & Spanish \\
\hline Informants & CGr & Informants & CGr & Informants & CGr \\
0.20 & 0.19 & 0.73 & 1.10 & 0.77 & 0.64
\end{tabular}


(44)a. A: Can I have a glass of wine, please?

B: You must drive after the party: don't drink wine, have WATER instead!

b. A: Posso avere un bicchiere di vino perfavore? can.1SG have.INF a glass of wine please

'Can I have a glass of wine, please?'

B Devi guidare dopo la festa.

must.2SG drive.INF after the party

non bere VINO, bevi ACQUA piuttosto!

not drink.INF wine drink.IMP.2SG water rather

'You must drive after the party, don't drink wine, have WATER instead!'

Table 4. In situ CF in imperatives

\begin{tabular}{|l|l||l|l||l|l|}
$|l||l||l|$ & \multicolumn{2}{l|}{ Italian } & \multicolumn{2}{l|}{ Spanish } \\
\hline Informants & CGr & Informants & CGr & Informants & CGr \\
3.18 & 3.33 & 3.11 & 3.31 & 3.16 & 3.25
\end{tabular}

As for intonation, the elicited productions show that in situ CF is always (48/48) marked with a bi-tonal pitch accent, in which the tonic vowel can be aligned either with the high $\left(\mathrm{H}^{*}+\mathrm{L}\right)$ or with the low $\left(\mathrm{H}+\mathrm{L}^{*}\right)$ target. This alternation does not depend on syllabic structure, since the target words examined were mostly paroxytons (cf. note 24) and it seems rather connected to language-specific variations $\left(\mathrm{H}^{*}+\mathrm{L}\right.$ in English and $\mathrm{H}+\mathrm{L}^{*}$ in Spanish). This variation is also left for future systematic investigation on the acoustic correlates of fronted Foci. Consider now Figures 3 and 4 below, for an immediate comparison between English and Italian fronted CF:

Figure 3. In situ CF in English imperatives 


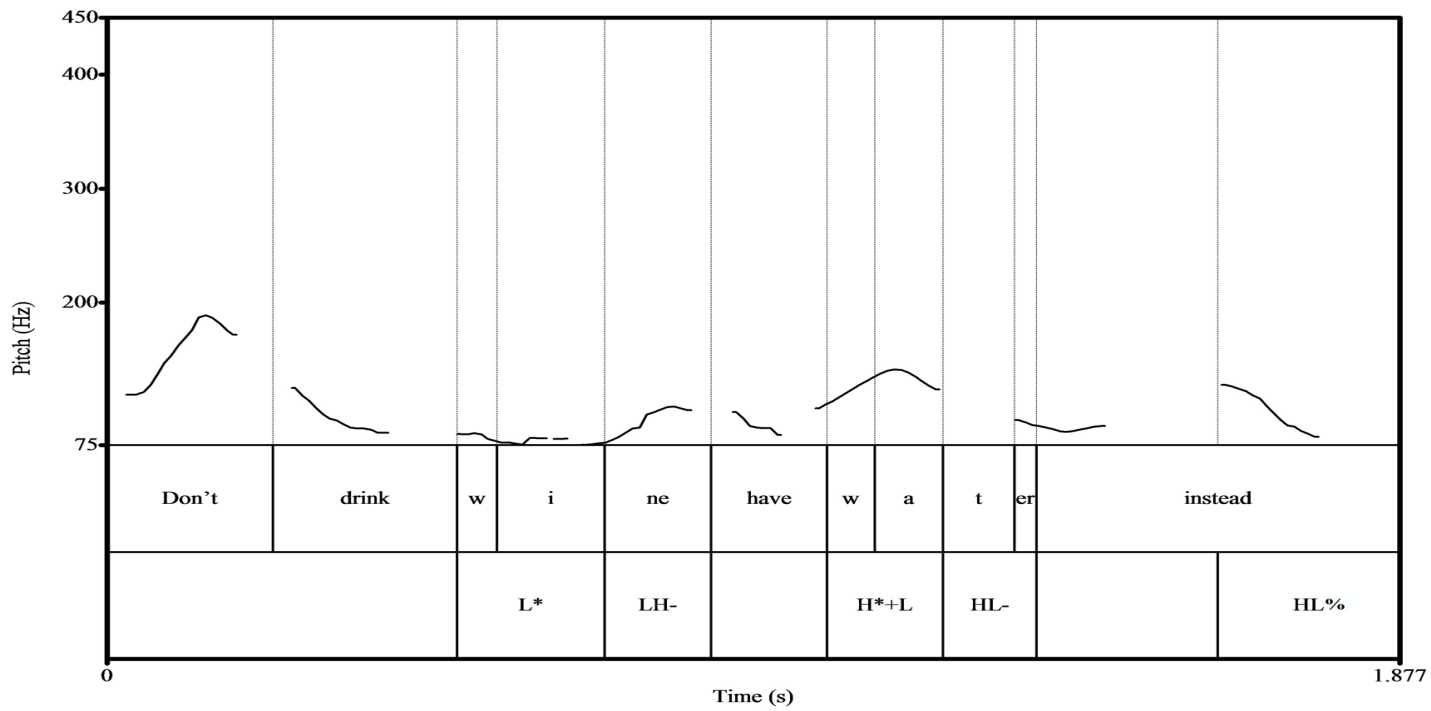

Figure 4. In situ CF in Italian imperatives

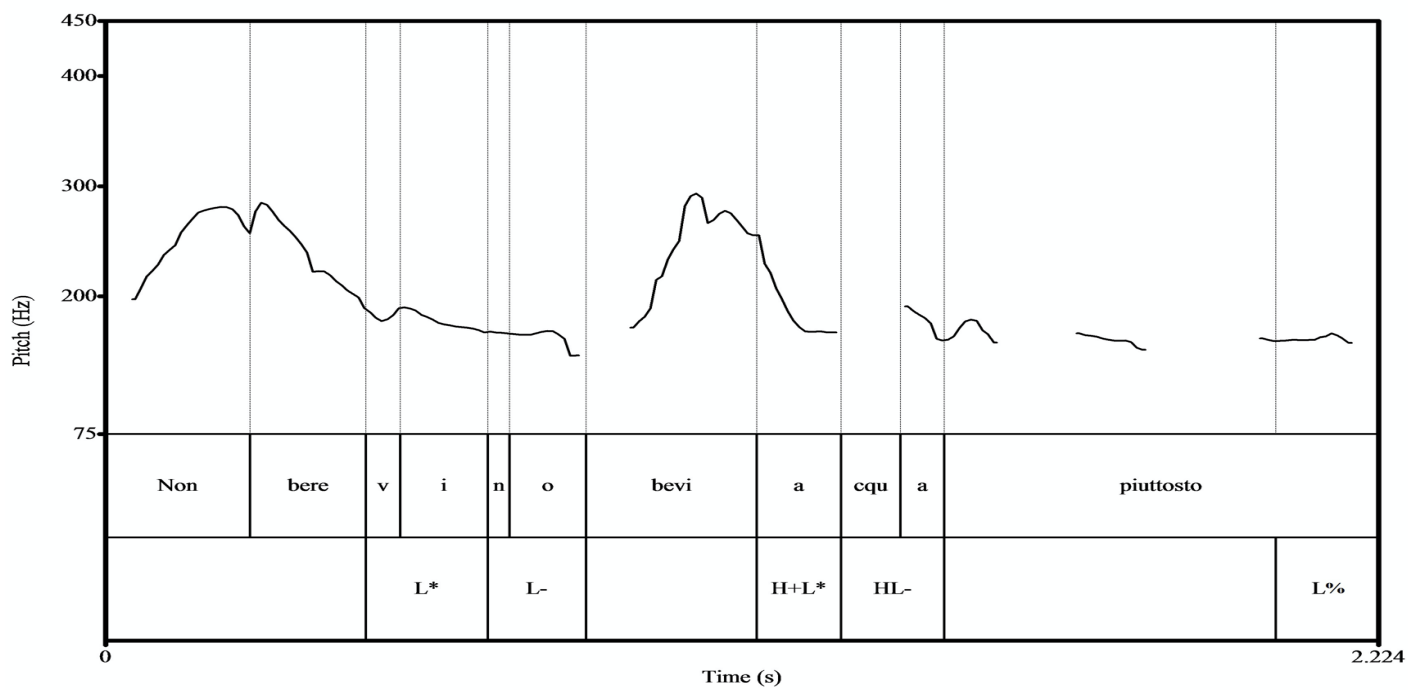

As it can be observed, in both Figures the tonic syllable stays low in the final part of the imperative downgrading contour, marking low boundaries within the relevant Intonational phrase.

Since in situ CF is fully accepted by informants, we must conclude that this discourse category is not excluded in imperative clauses. However, (i) it cannot be realized in the left periphery and (ii) it is not marked with a high pitch.

This result strongly differs from Bianchi et al.'s (2015) work, in which it is argued that $\mathrm{CF}$ can be realized both in the $\mathrm{C}$-domain and in situ, and is marked in both cases with a $\mathrm{L}+\mathrm{H}^{*}$ 
pitch accent. This discrepancy leads to posit that (i) in imperative clauses a CF cannot A'move to the left periphery because of a syntactic block (rather than for discourse-semantic reasons), which is not operative in the assertive clauses used in Bianchi et al. (2015) for their experiment, ${ }^{29}$ and (ii) the corrective feature is interpreted in a criterial position (cf. Rizzi 2006, 2007) in the C-domain; consequently, in the absence of $\mathrm{A}^{\prime}$-movement, the relevant constituent cannot be interpreted at the interfaces. ${ }^{30}$

Finally, comparing the behaviour of $\mathrm{CF}$ with what was attested for A-Topic and MF, we must conclude that $\mathrm{CF}$ is not a Type I root phenomenon (since it can be hosted by imperative clauses, at least in its in situ variant). The block on their fronted position will be dealt with later on in this paper.

\subsubsection{C-Topics in imperative clauses.}

The median values provided in Table 5 for C-Topics in imperative clauses reflect the fact that they are accepted in Italian and Spanish (with some variation that is, however, not significant; cf. Section 5.3 below), while they are marginal in English. Since the sentences in the test (and relevant contexts) were absolutely equivalent in the three languages, this discrepancy must be provided a comprehensive explanation.

Table 5. C-Topics in imperatives

\begin{tabular}{|c|c|c|c|c|c|}
\hline English & & Italian & & Spanish & \\
\hline Informants & CGr & Informants & CGr & Informants & CGr \\
\hline
\end{tabular}

\footnotetext{
${ }^{29}$ In other words, we can conclude that the semantics of correction in itself is not incompatible with an imperative clause, but a syntactic constraint prevents the CF from being fronted.

${ }^{30}$ On the other hand, it is possible to conjecture that the discourse properties of Corrective Foci are not exactly the same in the two positions and that focus fronting is triggered by some additional feature requirement that combines with correction, whose interpretation is basically in situ. Recent analyses have suggested, for instance, the possibility of an exhaustive character of fronted correction in some languages, on a par with Hungarian. However, since no systematic investigation has been conducted in this respect, as far as we know, we leave this question open for future research.
} 
\begin{tabular}{|l|l||l|l||l}
1.78 & 1.94 & 2.76 & 2.73 & 3.24
\end{tabular}

As for intonation, prosodic analysis shows that the dislocated phrases are realized with a bi-tonal $\mathrm{L}+\mathrm{H}^{*}$ pitch in 78 cases out of 98 (total occurrences are doubled because every target utterance in the test contains two sentences in this case, hence $2 \mathrm{C}$-Topics). This means that in the majority of cases $\mathrm{C}$-Topics are phonetically realized as a $\mathrm{F}^{0}$ rise with the peak aligned by the end of the TBU (as is shown in Figures 5 and 6 below). On the other hand, 20 realizations show a simple $\mathrm{H}^{*}$ pitch accent; this realization generally occurs on the second $\mathrm{C}$-Topic of the sequence (i.e., on the C-Topic located in the left periphery of the second sentence of the sequence), but no systematic behaviour could be attested.

(45)a. A Where can I put these flowers?

B: The roses put in the vase, the sunflower leave on the table.

Figure 5. C-Topics in English imperatives

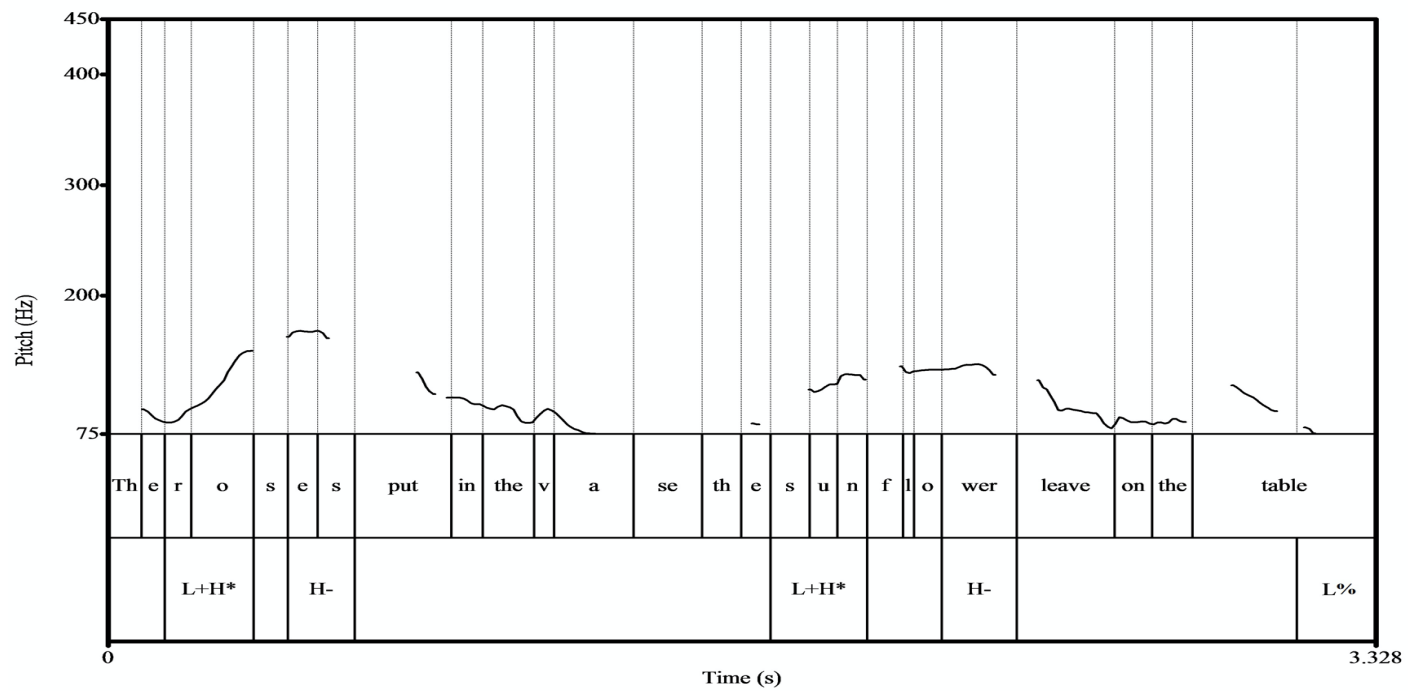

(45)b. A: ¿Dónde dejo estas flores?

where leave.PST.1SG these flowers

'Where shall I leave these flowers?'

$\begin{array}{lllll}\text { B: } & \text { Las } & \text { rosas, ponlas } & \text { en el jarrón; } \\ \text { the } & \text { roses put.IMP.2SG-them.CL in the vase } \\ \text { el girasol, déjalo } & \text { sobre la mesa }\end{array}$


the sunflower leave. IMP.2SG.it.CL on the table

'The roses put in the vase; the sunflower leave on the table.'

Figure 6. C-Topics in Spanish imperatives

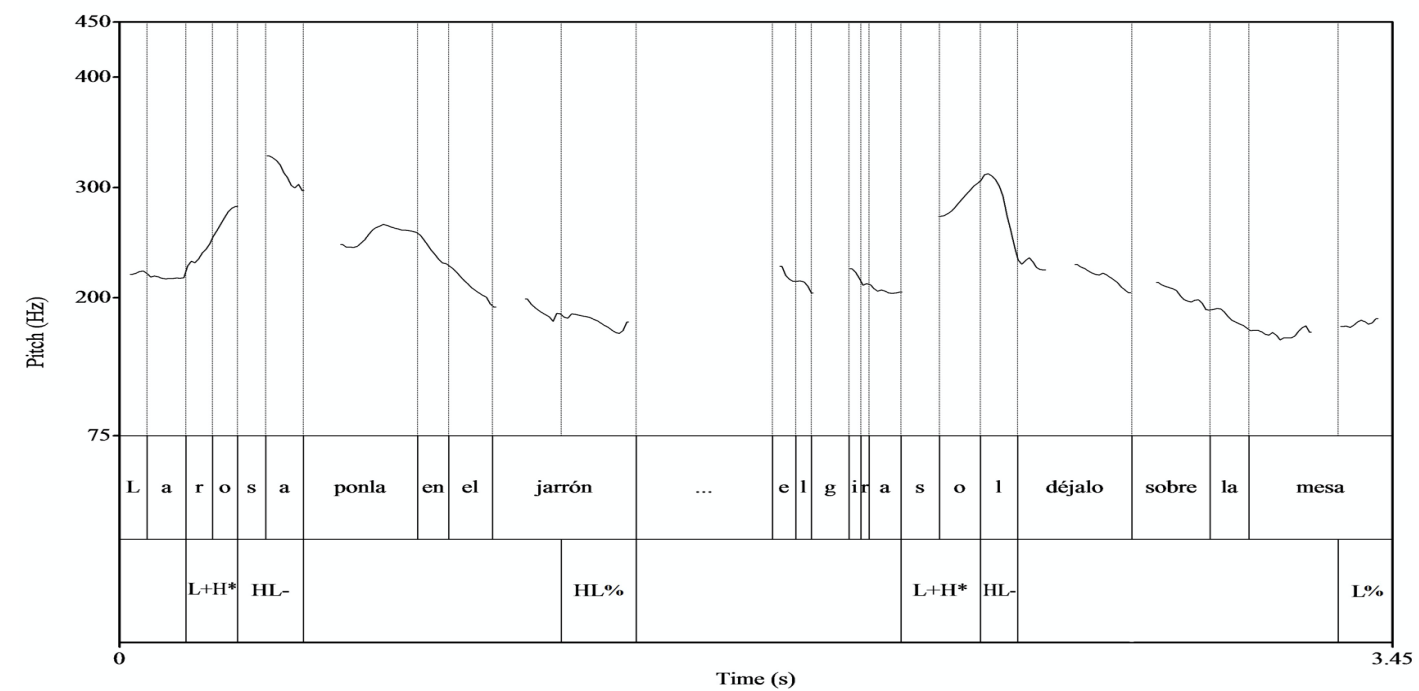

Based on this result, we can say that the expected prosodic properties are always met for CTopics since both $\mathrm{H}^{*}$ and $\mathrm{L}+\mathrm{H}^{*}$ are pitch accents connected to contrastive elements across languages (cf. § 3.2; see also Pierrehumbert 1980, Pierrehumbert \& Hirschberg 1990, Büring 2003, Kratzer \& Selkirk 2009, among many others). We can thus conclude that the relevant constituents are associated with the expected IS-interpretation and, as a consequence, that CTopics are allowed in imperative clauses.

Contrastive and Corrective discourse categories thus qualify as Type II root phenomena since both C-Topics and in situ CF are accepted in imperative clauses. However, C-Topics are not (fully) accepted in English and, in this respect, they show the same behaviour as fronted $\mathrm{CF}$ (excluded in all the languages examined). This suggests the existence of a syntactic block, which will be treated in detail in Section 6.3.

Considering the behaviour of A-Topics/MF, on the one hand, and C-Topics/CF on the other, we can conclude that imperative clauses cannot host discourse phenomena with context update potential. Nevertheless, they cannot be considered less than propositions since they can host Type II root phenomena - a crucial claim for the purposes of the present investigation. 
Before dealing with the final analysis and the relevant proposal, let us finally consider the data concerning the realization of G-Topics.

\subsubsection{G-Topics in imperative clauses.}

G-Topics provide a picture in which they are marginal in English and only "mildly" accepted in Italian and Spanish. Consider Table 6 below:

Table 6. G-Topics in imperatives

\begin{tabular}{|l|l||l|l||l|l|}
$|l||l||l|$ & \multicolumn{2}{|l|}{ Italian } & Spanish \\
\hline Informants & CGr & Informants & CGr & Informants & CGr \\
2.12 & 2.42 & 2.63 & 2.72 & 2.73 & 2.54
\end{tabular}

This result could be expected in English for independent reasons since, as is argued in Bianchi \& Frascarelli (2010:21), no leftward topic structure is devoted to mere givenness marking in English (although givenness may be a concurrent property of topics), and the retrieval of given information is generally implemented through simple destressing (cf. also Neeleman \& Reinhart 1998, Schwarzschild 1999). However, this result was totally unexpected in Italian and Spanish, since G-Topics are not connected with CG management and should be allowed in any type of clause (cf. Section 3.3 above).

Furthermore, the prosodic analysis shows that acceptance was in fact connected to a different IS-interpretation (as in the case of A-Topics). Specifically, the informants who collaborated for the intonational analysis (i.e, those who accepted these structures in the online questionnaire) always produced the dislocated phrases with a bitonal $\mathrm{L}+\mathrm{H}^{*}$ pitch accent, that is to say, with the prosodic characterization of dislocated contrastive elements. Hence, they were feasibly interpreted as C-Topics. Consider sentences (46a-c) and relevant Figures 7-8-9 below: 
(46)a. A: Here you have the rice. What shall we do?

B: Listen to me: the rice, steam it!

Figure 7. Intended G-Topics in English imperatives

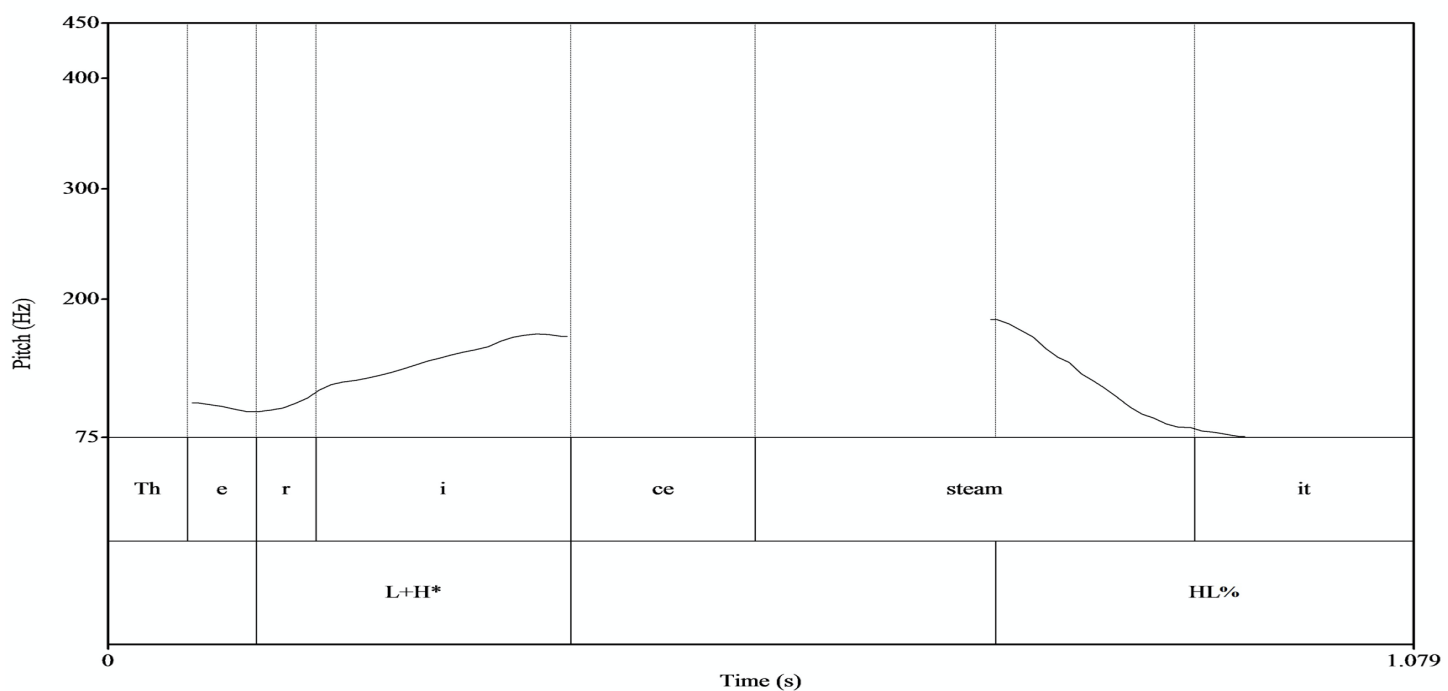

(46)b. A Aquí está el arroz. ¿Qué hacemos?

here stay.3SG the rice what make.1PL

'Here is the rice. What shall we do?'

B: Mira, iel arroz, cuécelo al vapor!

Look the rice cook.IMP.2SG-it.CL at.the steam

'Look, the rice you can steam!'

Figure 8. Intended G-Topics in Spanish imperatives 


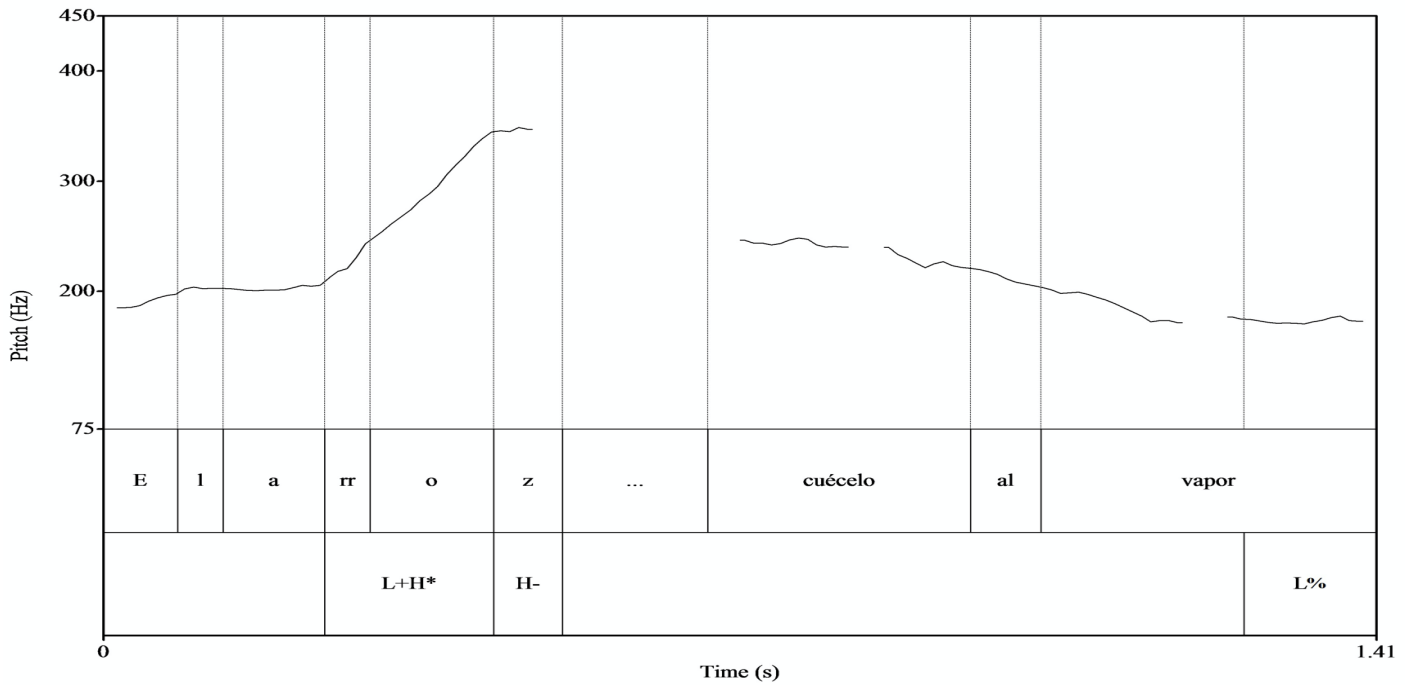

(46)c. A Ecco il pacco del riso. Che facciamo? here the pack of.the rice what make.1PL 'Here is the pack of rice. What shall we do?'

B: Senti, il riso, cuocilo cook.IMP.2SG-it.CL at steam
listen the rice a
'Listen, the rice cook it on steam.'

Figure 9. Intended G-Topics in Italian imperatives

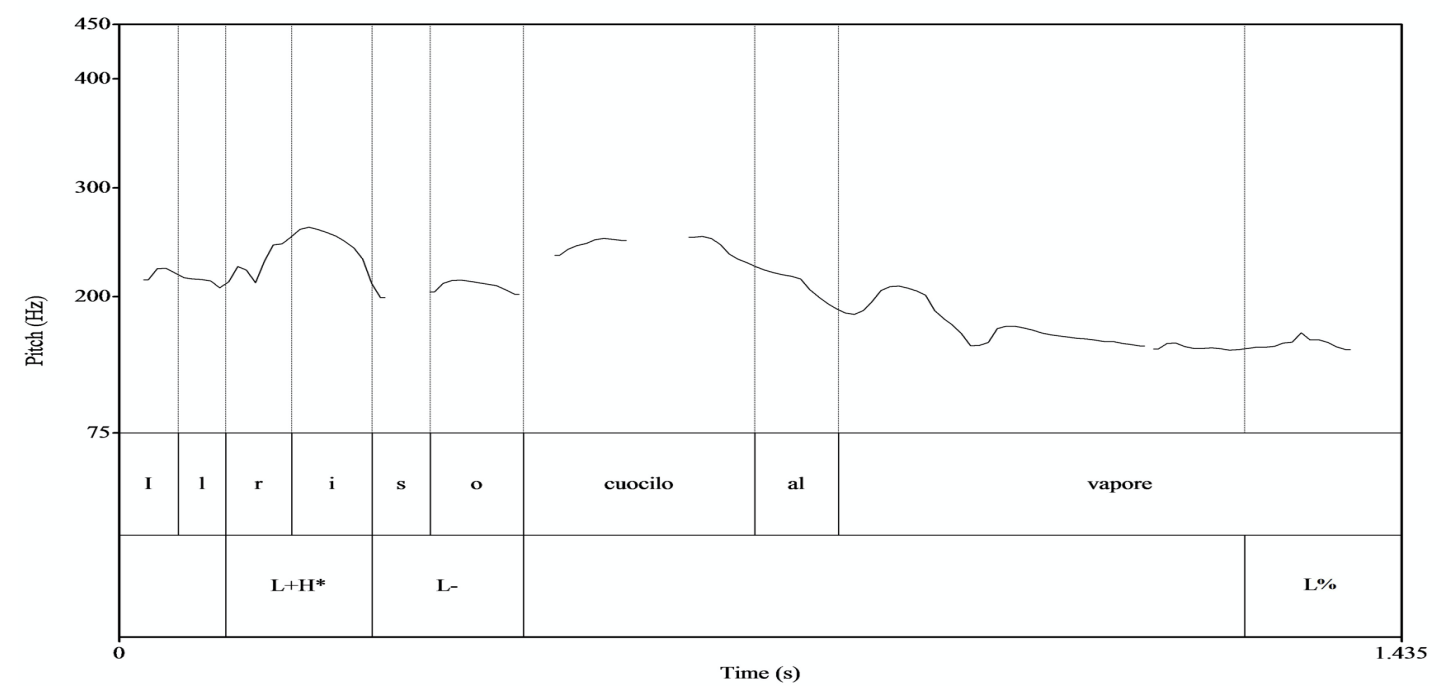

In these examples it is feasible to conjecture that the steaming of the contextually given ingredient (i.e., the 'rice') in the relevant sentence might have been interpreted as opposed to 
the cooking of some other type of food (not mentioned, but inferable via bridging in a 'cooking context', cf. Roberts' (2003); see also $\$ 3.3$ and note 13). At any rate, the crucial point is that no informant provided a low-toned realization for the dislocated constituents included in the section dedicated to G-Topics. Since G-Topics are allowed in every clausal type, this outcome must be provided an independent explanation, which will be addressed in the conclusive sections.

\subsection{Statistical significance and parametric technique: the ANOVA analysis of variance}

The acceptability judgments obtained have been analysed using the ANOVA test so as to (i) verify whether the factors involved have a significant effect on the acceptability variation between the different experimental conditions, and (ii) be able to answer the questions mentioned in Section 5.1.

In particular, the factors involved imply 'single entries' in two cases and, specifically, in the case of 'discourse category' (which are 5, namely, A-Topic, C-Topic, G-Topic, MF and $\mathrm{CF}$ ) and 'language' (which are 3, namely English, Italian and Spanish). Then, a third factor only concerned $\mathrm{CF}$, for which we wanted to evaluate the (possible) significance of its 'position' (whether in situ or fronted). As 'position' was not tested for any other discourse category (always located in the left periphery of the sentence), the CF case represented an exception and, as such, a complication for statistical analysis (since it is not appropriate to include a variance factor that only applies for one category out of five). We thus solved this problem producing two ANOVA tests: one considering A-Topic, C-Topic, G-Topic, MF and in situ $\mathrm{CF}$, the other considering A-Topic, C-Topic, G-Topic, MF and fronted CF.

Importantly, the results of the two ANOVA tests carried out show that the main effect ${ }^{31}$ of the factors involved is significant $(\mathrm{p}<0.05)$ in both cases. This can be seen in Tables 7 and 8 below, in which significant values are marked in red for each interaction. ${ }^{32}$

\footnotetext{
31 The main effect of an independent variable is the effect of that variable on the dependent one, ignoring the effects of all other independent variables.

${ }^{32}$ Tables 7 and 8 show for each factor and for their interactions the following data:
}

(a) Sum of Squares (SS): the sum of the squared deviations (i.e., differences from the mean); 
Table 7. Factors' main effect and their interactions with in situ CF

\begin{tabular}{|l|l|l|l|l|l||}
\hline \multirow{2}{*}{} & \multicolumn{5}{|l|}{$\begin{array}{l}\text { Repeated Measures Analysis of Variance (Long Table Format) } \\
\text { Sigma-restricted parameterization; Effective hypothesis } \\
\text { decomposition; Std. Error of Estimate: ,3058745 }\end{array}$} \\
\cline { 2 - 6 } & SS & DF & MS & F & p \\
\hline Intercept & $\mathbf{1 3 0 , 1 6 2 3}$ & $\mathbf{1}$ & $\mathbf{1 3 0 , 1 6 2 3}$ & $\mathbf{3 1 6 2 , 1 1 6}$ & $\mathbf{0 , 0 0 0 0 1 2}$ \\
\hline Error & 0,1235 & 3 & 0,0412 & & \\
\hline LANG & $\mathbf{4 , 9 2 5 9}$ & $\mathbf{2}$ & $\mathbf{2 , 4 6 3 0}$ & $\mathbf{2 1 , 4 1 3}$ & $\mathbf{0 , 0 0 1 8 5 6}$ \\
\hline Error & 0,6901 & 6 & 0,1150 & & \\
\hline CAT & $\mathbf{5 2 , 7 8 2 6}$ & $\mathbf{4}$ & $\mathbf{1 3 , 1 9 5 7}$ & $\mathbf{6 2 , 1 7 9}$ & $\mathbf{0 , 0 0 0 0 0 0}$ \\
\hline Error & 2,5467 & 12 & 0,2122 & & \\
\hline LANG*CAT & $\mathbf{2 , 7 0 8 0}$ & $\mathbf{8}$ & $\mathbf{0 , 3 3 8 5}$ & $\mathbf{5 , 1 0 7}$ & $\mathbf{0 , 0 0 0 8 6 0}$ \\
\hline Error & 1,5907 & 24 & 0,0663 & & \\
\hline
\end{tabular}

Table 8. Factors' main effect and their interactions with in situ CF

\begin{tabular}{|l|l|l|l|l|l||}
\hline \multirow{2}{*}{ Effect } & \multicolumn{5}{|l|}{$\begin{array}{l}\text { Repeated Measures Analysis of Variance (Long Table Format) } \\
\text { Sigma-restricted parameterization; Effective hypothesis } \\
\text { decomposition; Std. Error of Estimate: 3058745 }\end{array}$} \\
\cline { 2 - 6 } & SS & DF & MS & F & p \\
\hline Intercept & $\mathbf{2 3 7 , 6 0 2 0}$ & $\mathbf{1}$ & $\mathbf{2 3 7 , 6 0 2 0}$ & $\mathbf{2 5 3 9 , 5 8 8}$ & $\mathbf{0 , 0 0 0 0 1 7}$ \\
\hline Error & 0,2807 & 3 & 0,0936 & & \\
\hline
\end{tabular}

(b) Degree of Freedom (DF): the number of values that may vary in a statistic without violating any constraint;

(c) Mean Squares (MS): representation of population variance, obtained by dividing the SS by the DF;

(d) F-Value (F): the result of the F-test calculated by dividing the MS value by the MS error; it helps to verify whether the variance between the means of two populations is significantly different;

(e) P-value (P): the probability of getting a result at least as extreme as the one that was actually observed, given that the null hypothesis is true. If $\mathrm{p}<0.05$ the effect of the relevant factor/interaction is taken as significant. 


\begin{tabular}{|l|l|l|l|l|l|}
\hline LANG & $\mathbf{3 , 2 8 4 2}$ & $\mathbf{2}$ & $\mathbf{1 , 6 4 2 1}$ & $\mathbf{1 7 , 6 0 6}$ & $\mathbf{0 , 0 0 3 0 8 6}$ \\
\hline Error & 0,5596 & 6 & 0,0933 & & \\
\hline CAT & $\mathbf{6 0 , 7 4 6 6}$ & $\mathbf{4}$ & $\mathbf{1 5 , 1 8 6 7}$ & $\mathbf{8 6 , 8 8 4}$ & $\mathbf{0 , 0 0 0 0 0 0}$ \\
\hline Error & 2,0975 & 12 & 0,1748 & & \\
\hline LANG*CAT & $\mathbf{3 , 5 6 1 4}$ & $\mathbf{8}$ & $\mathbf{0 , 4 4 5 2}$ & $\mathbf{6 , 7 1 5}$ & $\mathbf{0 , 0 0 0 1 2 5}$ \\
\hline Error & 1,5910 & 24 & 0,0663 & & \\
\hline
\end{tabular}

It should be noticed that the interaction between the factors is also significant when compared two by two and, finally, that there is a significant interaction also between the factors if they are compared together.

These results provide statistical support to the claim that the variance attested in the investigation is not due to chance but, indeed, the possibility of hosting specific discourse categories in the left periphery of an imperative clause depends (i) on the discourse category and (ii) on the language.

The different acceptance attested for the in situ vs. fronted position of the CF is also significant for the 3 languages examined, as is shown in Table 9 below:

Table 9. Factors' main effect and their interactions for in situ vs. fronted CF

\begin{tabular}{|l|l|l|l|l|l||}
\hline \multirow{2}{*}{ Effect } & \multicolumn{5}{|l|}{$\begin{array}{l}\text { Repeated Measures Analysis of Variance (Long Table Format) } \\
\text { Sigma-restricted parameterization; Effective hypothesis } \\
\text { decomposition; Std. Error of Estimate: ,3058745 }\end{array}$} \\
\cline { 2 - 6 } & SS & DF & MS & F & p \\
\hline Intercept & $\mathbf{8 3 , 0 1 0 2 6}$ & $\mathbf{1}$ & $\mathbf{8 3 , 0 1 0 2 6}$ & $\mathbf{1 8 4 2 , 9 9 1}$ & $\mathbf{0 , 0 0 0 0 2 8}$ \\
\hline Error & 0,13512 & 3 & 0,04504 & & \\
\hline LANG & $\mathbf{0 , 3 3 9 7 9}$ & $\mathbf{2}$ & $\mathbf{0 , 1 6 9 8 9}$ & $\mathbf{1 5 , 3 3 5}$ & $\mathbf{0 , 0 0 4 3 8 0}$ \\
\hline Error & 0,06647 & 6 & 0,01108 & & \\
\hline CAT & $\mathbf{4 0 , 1 0 9 5 7}$ & $\mathbf{1}$ & $\mathbf{4 0 , 1 0 9 5 7}$ & $\mathbf{7 5 0 , 9 4 8}$ & $\mathbf{0 , 0 0 0 1 0 7}$ \\
\hline Error & 0,16024 & 3 & 0,05341 & & \\
\hline LANG*CAT & $\mathbf{0 , 4 7 0 9 7}$ & $\mathbf{2}$ & $\mathbf{0 , 2 3 5 4 9}$ & $\mathbf{7 , 7 1 2}$ & $\mathbf{0 , 0 2 1 9 6 9}$ \\
\hline Error & 0,18322 & 6 & 0,03054 & & \\
\hline
\end{tabular}


The analysis of standard deviations confirms the consistency and attainability of the present investigation since their value is always rather low. This shows that the average distance from the median values is never too large and, consequently, that the results attested are reliable. In particular, Table 10 below shows that the most dependable data concern CT, GT and in situ CF, whereas fronted CF and MF have clearly created major uncertainties to informants.

Table 10. Mean values and standard deviations for categories and languages

\begin{tabular}{|l|l|l|l|l|l|l|l||}
\cline { 3 - 8 } \multicolumn{2}{c|}{} & AT & CT & GT & MF & $\begin{array}{l}\text { In situ } \\
\text { CF }\end{array}$ & $\begin{array}{l}\text { Fronted } \\
\text { CF }\end{array}$ \\
\hline \multirow{2}{*}{ ITA } & mean & 1,09 & 2,76 & 2,63 & 0,59 & 3,11 & 0,73 \\
\cline { 2 - 8 } & St. dev. & 1,1901947 & 1,2995660 & 1,3378622 & 0,9548604 & 1,0427106 & 1,0582323 \\
\hline \multirow{2}{*}{ SPA } & mean & 1,79 & 3,24 & 2,73 & 0,33 & 3,16 & 0,77 \\
\cline { 2 - 8 } & St. dev. & 1,4112318 & 0,8973735 & 1,2574260 & 0,7823406 & 0,9512920 & 1,0881123 \\
\hline \multirow{2}{*}{ ENG } & mean & 1,20 & 1,78 & 2,12 & 0,12 & 3,18 & 0,20 \\
\cline { 2 - 8 } & St. dev. & 1,1862754 & 1,4877976 & 1,4759878 & 0,4774156 & 0,9591423 & 0,6222048 \\
\hline
\end{tabular}

We conclude this section with an illustration of the statistical data provided through a diagram (Figure 10 below), which allows for an immediate comparison between the mean values attested for the discourse categories examined across the three languages at issue:

Figure 10. A cross-linguistic comparison of the data examined 


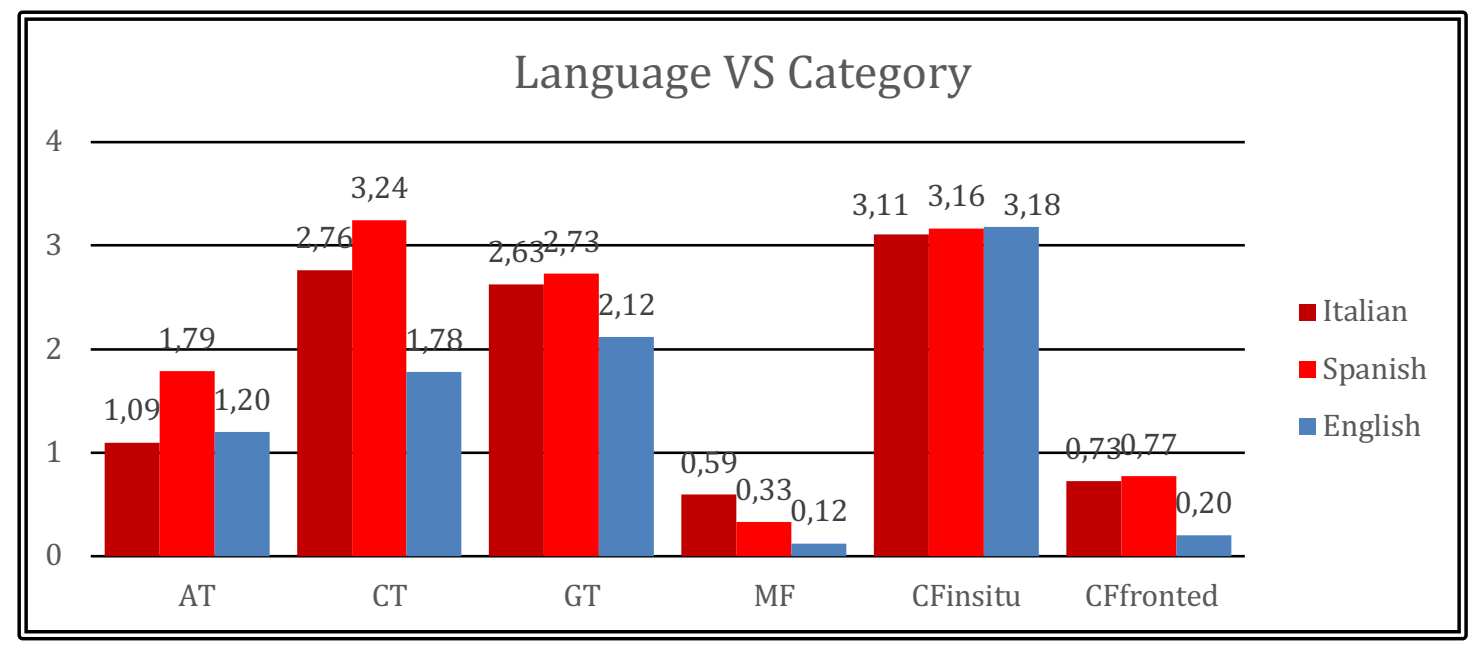

As is clear, results are very consistent and the only major difference attested concern the acceptability of CT and fronted CF in English, which will be treated in detail in Section 6.2 below.

\subsection{To sum up: interim conclusions}

The interface data illustrated so far have shown that the distinction between Type I and Type II root phenomena, and the IRR, have provided valid diagnostics for the purposes of the present investigation since results are very consistent cross-linguistically and the variation attested between categories, languages, positions and their interaction is always statistically significant. In particular, the present interface analysis has shown that:

(A) Type I root phenomena (AT and MF) are not allowed in imperative clauses;

(B) Type II root phenomena (CT and CF) are allowed, but a restriction is imposed on $\mathrm{CF}$ fronting across languages and on C-Topics in English;

(C) G-Topics, which should be allowed in all clausal types, are very marginally accepted in all the languages examined.

Result (A) leads to the conclusion that imperative clauses are not CG-active propositions, hence they do not have an impact on the shared components of the discourse structure and cannot update the $\mathrm{CG}$, and result (B) shows that they cannot be considered less than propositions. Hence, an independent explanation must be provided to account for the fact that in imperatives (a) CF cannot be fronted and (b) G-Topics are only marginally accepted. 
Based on these results and considerations, we can now turn to our interface proposal, approaching separately the G-Topic issue and the syntactic block described in (B). ${ }^{33}$

\section{A Syntax-Semantic interface approach: the proposal}

\subsection{The semantic perspective}

Aiming at a comprehensive interface account for both the patterns and the inconsistencies emerged in the present investigation, as said in Section 2.1, we draw from Farkas \& Bruce (2010) a componential view of the discourse context, connecting the presence of specific discourse categories to the different update potential of sentences (cf. also Roberts 2004).

Trying to provide a simplified description of a complex proposal, Farkas \& Bruce (2010) claim that an assertion move will update three context components, namely (a) the expressed proposition $p$ is added to the set of Discourse Commitments (DC) ${ }^{34}$ of speaker $s$, (b) the sentence, and the proposition $p$ it expresses, is pushed on top of the Table $e^{35}$ and $p$ becomes the at-issue proposition (i.e., the current conversational goal); (c) the item placed on the Table simultaneously projects a (set of) future $\mathrm{CG}^{36}$ relative to the issue on the Table (the so called 'Projected Set'). When the asserted proposition placed on the Table is accepted by all

33 This interface proposal is of course based on the three languages examined and on the data collected. Future work is needed to check and eventually extend its cross-linguistic validity.

34 The Discourse Commitment (for each discourse participant $\mathrm{x}$ ) is the (possibly empty) set of propositions that $\mathrm{x}$ has publicly committed to during the conversation (up to a given moment) and which have not (yet) become mutual commitments of all the participants (at the relevant given moment).

${ }^{35}$ The Table is a stack, which records what is at issue at any given point in the conversation. The items on the Table are syntactic objects (e.g., declarative or interrogative clauses) paired with their denotations. When the Table is not empty, the immediate goal of the conversation is to empty it, i.e. to settle the issue at hand.

${ }^{36}$ Notice that in Farkas \& Bruce's (2010) dynamic view, the CG is the set of propositions that have been accepted by all participants at a given moment, together with all the propositions that represent the shared background knowledge of the participants. 
participants, it is added to the CG and is removed from the DC set of each confirming participant (i.e., the $C G$ update is completed). In the case of a question, (a) no discourse commitment is added, (b) a set of $n$ propositions is pushed on the Table (with $n=2$ for polar questions and $n \geq 2$ for wh-questions) and (c) the Projected Set records $n$ possible future evolutions of the CG (each one corresponding to the update of the CG by one of the possible answers to the question).

These components take care of CG-oriented discourse moves (i.e., questions and assertions). However, following Krifka's (2007) bi-partition of the CG management (cf. discussion in Section 1 and note 9), the contribution of imperative clauses only concerns the (ADDRESSEE's) To-Do-LIST, which is specifically updated by this type of directive acts. Therefore, imperatives are classified as non 'CG-active' clauses.

Going through the different discourse categories examined above, we can thus argue that A-Topics are excluded in imperatives because they implement a conversational move and their main function is to define the entry that identifies the file card under which the proposition expressed in the sentence is to be stored (cf. Reinhart 1982 and Section 3.1). This discourse function is incompatible with non CG-active propositions. Notice that this conclusion is not in contrast with Krifka's (2001: 25) claim (i.e., that a command can follow an A-Topic, cf. quotation in $\$ 3.1$ above): our data exclude the presence of an A-Topic in an imperative clause, but not in a deontic (hence, assertive) declarative clause expressing a command.

The lack of CG-active update potential also explains the unacceptability of MF in imperatives: this discourse function must have access to (and potentially update) the CG, since it requires the hearer's evaluation with respect to something that is assumed to be in contrast with shared knowledge. Hence it is incompatible with clauses whose directive import updates the Addressee's To-Do-LisT.

As for $\mathrm{CF}$, since it is allowed in situ, we must conclude that its exclusion from the left periphery does not depend on an interpretive clash or a semantic incompatibility with non CG-active propositions. Furthermore, since imperatives are not assertions, we must conclude that $\mathrm{CF}$ does not necessarily imply the rejection of an assertion (as is argued in Bianchi \& Bocci 2012), but also of a non CG-active proposition; in other words, an imperative can be removed from the Addressee's TO-DO-LIST and substituted. In a nutshell, all Type I root phenomena (except in situ CF) are excluded from imperatives, as predicted in our hypothesis. 
As for Type II root phenomena, the acceptability of C-Topics in Italian and Spanish imperative clauses is consistent with the view of imperative clauses as (non CG-active) propositions (in line with Jiménez-Fernández and Miyagawa's 2014 claim that C-Topics are compatible with asserted and non-asserted complement clauses). Hence, their marginality in English imperatives cannot be given a discourse-semantic motivation. In this respect, we reckon that an explanation can be provided in terms of a syntactic block, the same operating on fronted CF cross-linguistically (cf. relevant discussion in Section 6.2 below). In the same spirit, since G-Topics are allowed in all clausal types, their rejection in the left periphery cannot be due to a discourse-semantic incompatibility and the explanation should be rather approached - also in this case - from a syntactic perspective (see Section 7 below).

\subsection{The syntactic mapping}

Since imperatives have been classified as non CG-active propositions, in order to account for their syntactic-semantic interface properties we propose that they are merged as sentences in which the assertive illocutionary force is not realized ${ }^{37}$ Nevertheless, we are not assuming a 'truncated' or simplified CP. Sticking to a cartographic CP-split account, we maintain the presence of the full hierarchy of projections in which, however, some features may remain 'inactive' or not accessible (as it is often assumed in the literature for different projections). We thus propose that in imperative clauses the assertive feature in ForceP is inactive and so are, as a consequence, all the projections connected to its activation (e.g., the projections hosting A-Topics and MF).

Furthermore, in line with recent analyses in which Ross' (1970) Performative Hypothesis has been revived and re-elaborated in syntactic (also cartographic) terms, we assume that the imperative clause is dominated by a Speech Act Projection (SAP, cf. Speas \& Tenny 2003,

\footnotetext{
${ }^{37}$ From a semantic/pragmatic perspective, imperatives have been suggested to be (main) clauses which lack assertion (Chierchia \& McConnell-Ginet 1990, Reis 1999, Zanuttini \& Portner 2003). These works always compare imperatives with declaratives and interrogatives, implicitly implying that they are main clauses. We highlight this idea in our proposal by providing a formal analysis that captures this semantic property.
} 
Speas 2004, Portner, Pak \& Zanuttini 2019) including the actual participants in the Speech Act, namely the SPEAKER and the ADDRESSEE (cf. also Bianchi 2006). Since it is generally assumed that the representation of the speech act applies to matrix declarative clauses (cf. Haegeman 2014, Haegeman \& Hill 2013, Hill 2007a,b, 2008, Miyagawa 2012, Haegeman \& Miyagawa 2016, among others), the originality of the present proposal lies in its extension of the SAP application to non CG-active propositions, as imperatives are argued to be in this work.

In the absence of an assertive illocutionary force, we propose that the imperative interpretation depends on a Modality feature (call it [+imp]), encoded in a specific projection of the split IP-domain. ${ }^{38}$ Drawing from Zanuttini's (2008) analysis, we assume the existence of a Jussive Phrase (JussP) and propose that this is the head in which the [+imp] feature is encoded as a formal syntactic feature. Following current minimalist theory (Chomsky 2008, Adger \& Svenononius 2011), features create syntactic dependencies for interpretation. Hence, the $[+\mathrm{DIR}]\left(\right.$ ective) feature encoded in the C-domain of the imperative clause (possibly in Fin ${ }^{\circ}$, since Force ${ }^{\circ}$ is inactive) acts like a probe and enters an Agree relation with the Juss ${ }^{\circ}$ head (as in (47)):

\footnotetext{
${ }^{38}$ The existence of a Modal Operator to account for the semantics of imperatives is also proposed in Schwager (2006), Kaufmann (2012), Oikonomou (2016). Their approach is however different from the present one, since these authors do not consider the syntactic mapping of this Operator and, most importantly, they treat imperatives as modal declarative sentences. Therefore, their account cannot explain why imperatives cannot be used as assertions. The existence of an Assert Operator and the consequent characterization of imperatives as non CG-active propositions, on the other hand, can provide a comprehensive explanation and qualifies the present proposal as totally innovative.
} 
(47)

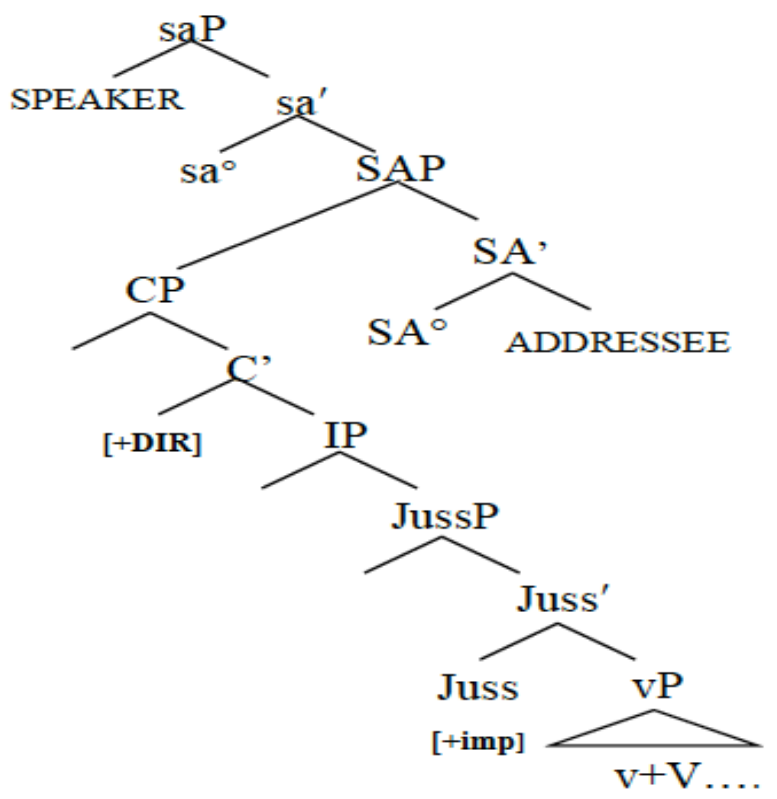

In languages like Italian or Spanish this dependency is created with the verb moving to Juss ${ }^{\circ}$, where it checks the relevant inflectional properties. On the other hand, if Pollock (1989) is correct when comparing V-to-I movement in French and English, V remains low in English. In our system, this is reflected in the fact that $\mathrm{V}$ stays in situ in English, whereas it undergoes movement to Juss ${ }^{\circ}$ in Spanish and Italian. Accordingly, the configuration for English imperatives will be as is shown in (48):

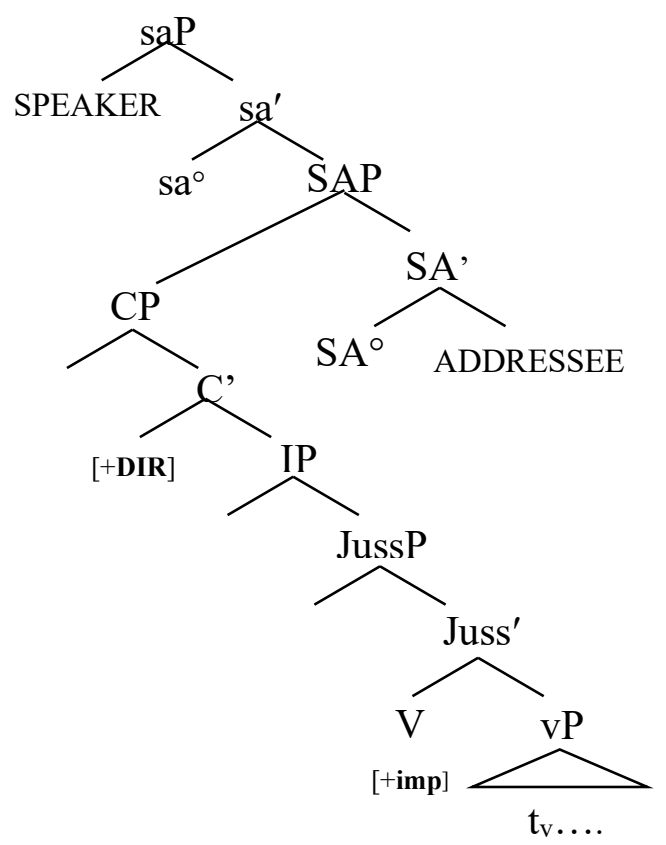


This distinction between English and Italian/Spanish is borne out by the relative positions of $\mathrm{V}$ and adverbs such as always, since most naturally in a language like Spanish and Italian this adverb occurs after the imperative V (cf. (49) and (50)), whereas the opposite holds for English (51): ${ }^{39}$

$\begin{array}{ccllll}\text { a. } & \text { *Siempre } & \text { lee las instrucciones } & \text { con } & \text { cuidado. } \\ \text { b. } & \text { *Sempre } & \text { leggi le } & \text { istruzioni } & \text { con } & \text { cura. } \\ & \text { always } & \text { read.IMP.2SG } & \text { the instructions } & \text { with } & \text { care }\end{array}$

(50)a. Lee siempre las instrucciones con cuidado.

b. Leggi sempre le istruzioni con cura.

'Always read the instructions carefully.'

(51)a. (Do) always read the instructions carefully.

b. *Read always the instructions carefully.

As shown above, the relative position of $\mathrm{V}$ in the languages under exam differs and this can be given a principled account if our suggestions that $\mathrm{V}$ only moves to $\mathrm{Juss}^{\circ}$ in (languages like) Italian/Spanish is correct. In those cases, in English where do is optionally present, we can simply assume that it fills the $\mathrm{Juss}^{\circ}$ head thereby valuing the [+imp] feature.

The structural account presented in this section can provide a comprehensive explanation for the discourse-semantics properties shown by imperatives (i.e., the consistent ban imposed on Type I root phenomena) and their complement-like quality.

Furthermore, the existence of a SAP can offer an explanation to the 'antiagreement' effects that characterize imperative clauses (cf. Section 4.2 above). Specifically, assuming that grammatical agreement starts out at C (cf. Chomsky 2005) and adapting Miyagawa's (2010, 2012, 2017) analysis, we propose that a sort of 'allocutive agreement' is operative in imperative clauses as well (i.e., a default agreement with the ADDRESSEE). In particular,

\footnotetext{
${ }^{39}$ Not considering the Split-IP hypothesis, we assume here, with Pollock (1989), that adverbs such as always are generated within VP.
} 
Miyagawa (2012) proposes that in languages like English subject agreement lowers to $\mathrm{T}$, while in languages like Basque, two agreement features occur in $\mathrm{C}$ : one lowers to $\mathrm{T}$ to form the typical subject-verb agreement, while the other stays at $\mathrm{C}$ where it agrees with the ADDRESSEE to form the allocutive agreement (cf. Ohyarçabal 1993).

Extending this proposal, we suggest that this parameter can also operate interlinguistically and distinguish between different types of agreement in different clause types. Hence, even though in a given language agreement lowers to $\mathrm{T}$ in declarative clauses, it can stay in the C-domain in imperatives (tentatively in Fin ${ }^{\circ}$, following Rizzi’s 1997 association between FinP and agreement/finiteness) and agree with the allocutive probe in $\mathrm{SA}^{\circ}$, as we can observe in (52):

(52) $\left[\right.$ saP SPEAKER $\left[\right.$ sa' Sa $\left[\mathrm{SAP}\left[\mathrm{CP}\left[\mathrm{C}^{\prime}[+\mathrm{DIR}][\right.\right.\right.$ FinP

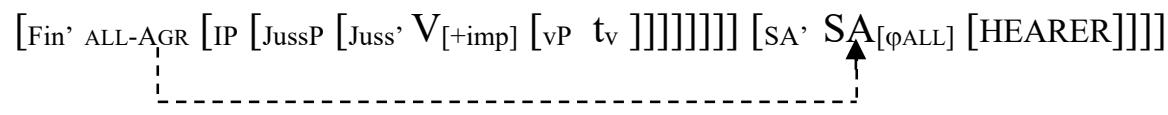

We thus propose that $2^{\text {nd }}$ person agreement in imperative clauses is due to allocutive agreement. Nevertheless, considering the relevant Agree relation as a parametric option, the possibility is left open that in some languages (or sentence type, both inter-linguistically and cross-linguistically) allocutive agreement is not realized and an alternative form of agreement is expressed in the imperative clause.

We can now finally resume and provide an explanation for the asymmetry emerged (in all the languages examined) between fronted and in situ $\mathrm{CF}$ and the block on C-Topics in English.

6.3 The fronting of discourse-related categories in imperative clauses: an intervention account

Based on the analysis proposed in Section 6.2, we suggest that the asymmetries concerning fronted $\mathrm{CF}$ and $\mathrm{C}$-Topics can be provided an immediate and comprehensive explanation considering their syntactic derivation.

As is known, CF fronting and Topicalization (the operation deriving C-Topics in English; cf. among others Haegeman 2004, Emonds 2004, Maki, Kaiser \& Ochi 1999, Bianchi \& 
Frascarelli 2010) are derived through A'-movement, whereas CLLD languages implement different strategies for Topics. Specifically, in languages like Italian (all types of) Topics are merged in the $\mathrm{C}$-domain and associated with a clitic pronoun in argument position (cf. Cinque 1990, Frascarelli 2000, 2017), while in languages like Spanish G-Topics and C-Topics move to Spec,TP (cf. Jiménez-Fernández \& Miyagawa 2014). This means that fronted CF (crosslinguistically) and C-Topics in English A'-move to the C-domain, determining an intervention effect (cf. footnote 7 above; see also Haegeman 2012) with the allocutive probing operation (53a), while this is not the case in languages like Italian (53b) and Spanish (53c):

(53)a. *(TOP languages like) English:

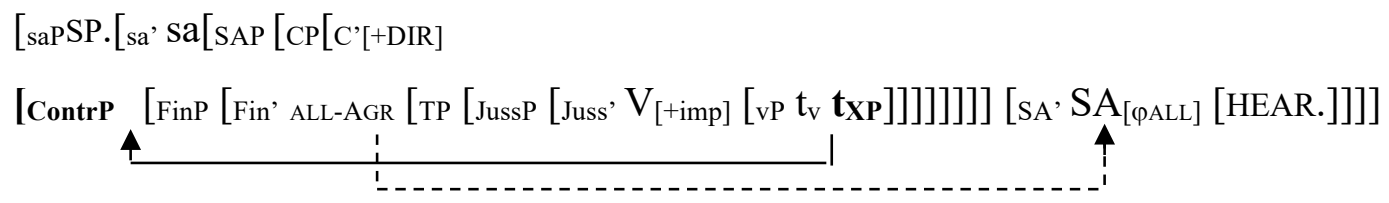

b. (CLLD languages like) Italian:

[ $\mathrm{saPSP}\left[\mathrm{sa}^{\prime} \mathrm{Sa}\left[\mathrm{SAP}\left[\mathrm{CP}\left[\mathrm{C}^{\prime}[+\mathrm{DIR}]\right.\right.\right.\right.$

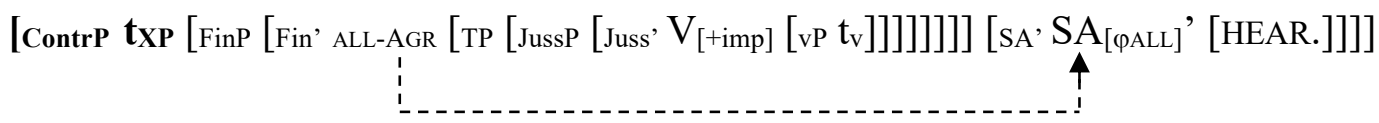

c. (CLLD languages like) Spanish:

[saPSP.[sa' Sa[SAP [CP[C'[+DIR]

[ContrP [FinP [Fin' ALL-Agr [TP [JussP [Juss' $\left.\left.\left.\left.\left.\left.\mathrm{V}_{[+\mathrm{imp}]}\left[\mathrm{vP} \mathrm{t}_{\mathrm{v}} \mathbf{t}_{\mathbf{X P}}\right]\right]\right]\right]\right]\right]\right]$ [SA' $\left.\left.\mathrm{SA}_{[\varphi A L L]}[\mathrm{HEAR}].\right]\right]$

Assuming for fronting the same type of Operator movement described for C-Topic in (53a), the block imposed on fronted CF - attested across languages (cf. Table 2 above) - can be also attributed to an intervention effect. This means that no inconsistencies are at stake: the block is due to independent (syntactic) reasons and CF and C-Topics can be consistently characterized as Type II root phenomena, without further ado for the present interface proposal. ${ }^{40}$

\footnotetext{
${ }^{40}$ We acknowledge (following a reviewer's suggestion) that reading sentences that were created for a written test is not an optimal testing design for a prosodic evaluation and, consequently, further research is needed to validate this conclusion. Nevertheless, since the outcome proposed is very
} 
It should be noticed that we are taking intervention as a by-product of movement for evaluation; hence when two chains interfere intervention shows up. This recalls Richards' (1999) intervention effect caused by crossing chains, instead of nesting chains. Crossing chains are only allowed in multiple movements to multiple Specifiers of a single head. In our case, allocutive agreement and CLLD involve different heads. Accordingly, no crossing of the relevant chains is permitted. This can explain the intervention effect exhibited in English (cf. (53a)). On the other hand, in Italian C-Topics directly merge in ContrP, so that no crossing is at stake for the allocutive chain (cf (53b)). Finally, in Spanish C-Topics move to TP (JiménezFernández \& Miyagawa 2014) and, consequently, the two chains are nesting into each other, creating no intervention effect ( $\operatorname{cf}(53 \mathrm{c})$ ). The latter option is also attested in cases where we combine A-movement and A'-movement, as in wh-questions. Since the two resulting chains are nesting, no blocking arises. For further discussion on the role of nesting vs. crossing chains in intervention effects, see Jiménez-Fernández (2011).

The intervention effect created by the allocutive agreement raises the question as to whether initial adjuncts can occur in imperatives. Assuming Haegeman's (2012) view that (at least some) initial adjuncts are base-generated in an initial position, the prediction is that (given there is no intervention) they are totally compatible with imperatives. This prediction is borne out by data, as illustrated in the following examples:

(54)a. When you're ready, give me a call.

b. At three o'clock, come to my office and we will talk.

Since there is no intervention due to the non-movement character of these adjuncts, they can perfectly occur in the left periphery of imperatives. ${ }^{41}$

consistent across informants, we reckon that the present result can be given as conclusive in this investigation.

${ }^{41}$ It could be objected that fronted adjuncts are compatible with imperatives in English (and presumably in the other languages they deal with), as is shown in (i) and (ii) below:

(i) When you're ready, give me a call.

(ii) At three o'clock, come to my office and we will talk.

However, initial adjuncts like the ones exemplified in (i) and (ii) are 'a different type of A'constituents'. They are not Topics, but more properly qualified as (temporal) 'frames' (using Chafe's 
As for the case of G-Topic, it will be treated below in a separate Section, since it implies a wider reflection on the interplay between prosody and syntax.

\section{Back to G-Topics: Conversational dynamics at the prosodic Interface}

As we have seen, G-Topics are either very marginal or rejected in the left periphery of imperative clauses. Since they are either merged in the C-domain or moved to Spec,TP in CLLD languages, relevant unacceptability cannot be attributed to the same syntactic block that was argued for fronted CF. Similarly, a discourse-semantic block cannot be invoked, since G-Topics are assumed to be available in all types of clauses.

Based on the observation that G-Topics can be realized in the right periphery of an imperative clause, as well as in other types of directive speech acts (see (55)-(56) below), we can conclude that the exclusion of G-Topics in the left periphery of imperative clauses must be due to a prosodic constraint and, specifically, to a spell-out incompatibility between an initial low-toned constituent and the $\mathrm{H}^{*}+\mathrm{L}$ intonation associated with imperative clauses. In other word, our claim is that the relevant 'block' can be attributed to an interface strategy emerging to avoid a prosodic clash (on the relevance of clash-avoidance strategies cf. Nespor \& Vogel 1979, Prieto 2011, among others; on directive intonation cf. Pierrehumbert \& Hirschberg 1990 and the discussion in $\S 5$ above).

As a piece of evidence, consider sentences (55) and (56) below, which are part of an independent test, elaborated for the purposes of this proposal (with the collaboration of 15 informants from each of the examined languages):

$\begin{array}{cllllll}\text { (55)A: Non } & \text { voglio } & \text { mangiare } & \text { carote: } & \text { le } & \text { odio. } \\ \text { No } & \text { quiero } & \text { comerme } & \text { las } & \text { zanahorias: } & \text { las } & \text { odio. } \\ \text { not } & \text { want.1SG } & \text { eat.INF } & \text { the carrots } & \text { them } & \text { hate.1SG }\end{array}$

1976 traditional term, resumed and discussed in Krifka 2007). Hence, they are not 'entities', which is the semantic property that we assume for Topics (following Reinhart 1982), and their treatment is beyond the scope of this paper. 
'I don't want to eat carrots: I hate them.'

B: Mangiale, le carote: sono buone per la salute!

Cómetelas, las zanahorias: ison buenas para la salud!

eat.IMP-them.CL the carrots: be.3PL good.F.PL for the health

'Eat your carrots, instead: they are good for you!'

(56) A: Non voglio mangiare carote: le odio.

not want.1SG eat.INF carrots them hate.1SG

No soporto comer zanahorias; no me gustan nada

not bear.1SG eat.INF carrots not to.me please.3PL nothing

'I don't want to eat carrots: I hate them.'

B: Dovresti mangiarle, le carote: sono buone per la salute! deberías comerte las zanahorias: ¡son buenas para la salud! should.2SG eat.INF-them.CL the carrots: be.3PL good.F.PL for the health 'Eat your carrots, instead: they are good for you!'

As is clear, in these cases no prosodic clash can be produced with the final L\% boundary of the imperative clause (see Figures in Section 5) and the relevant sentences are fully accepted by informants.

To conclude, always sticking to a cartographic account in which the full hierarchy of projections is maintained (cf. also §6.2), no ad hoc restriction should be sought for the imperative C-domain: the cross-linguistic exclusion of G-Topics from imperatives is due to an interface incompatibility between the raising intonative contour of imperative clauses and the presence of a low-toned constituent in the left periphery. This also supports that idea that phonological information is encoded in the lexicon in the form of syntactic features (i.e., a pfeature associated with a dedicated functional projection; cf. Adger and Svenonius 2011), which are made visible to the PF interface.

Hence, neither A-Topics or G-Topics are accepted in imperatives, but for different interpretive reasons at the interfaces. A-Topics are not allowed on discourse-semantic grounds: imperatives cannot host Type I root phenomena because they are non-CG-active propositions, that is to say, they are not endowed with update potential in the CG. On the other hand, the unacceptability of G-Topics is 'milder' because it depends on a prosodic 
incompatibility (not on discourse-semantic reasons). As for English, they are also excluded for independent reasons (cf. discussion after Table 6 above).

A final note regarding the presence of Force (though non-assertive Force) in imperatives is connected with the possible occurrence of imperatives in relative clauses. As illustrated by the following English examples (from Haegeman 2012: 120-121), imperatives are fully compatible with relatives:

(57)a. But there is, despite the book's brevity, and the fact that it is enormously pleasurable to read (at which point let me salute the translation) much going on. (Guardian 04.12.2010, page 13, col. 5)

b. He was at it again on last week's Desert Island Discs, still complaining that the world - for which read the music press - does not appreciate his genius. (Observer 6.12.2000, page 23 , col. 3)

c. The top speed (which please don't try to reach) is 220 miles an hour (Ferrari test driver BBC Radio 5, Andrew Radford, p.c.)

If Rizzi (1997) is correct when he claims that relative operators move to Spec,ForceP, the conclusion is that imperatives also hold a ForceP whose Spec can be the target of a relative operator. This is precisely the case in examples (58), which support the idea that some sort of Force must be present in imperatives. This is in line with our proposal, though our claim is that imperative are not assertion but non CG-active propositions.

\section{Conclusions: The C-domain of imperative clauses at the interfaces}

In the present work a novel syntactic analysis for imperative clauses has been proposed, crucially based on an interface investigation. Consistent evidence has been provided that in the left periphery of imperative clauses the availability of information-structural categories is partially restricted. However, rather than assuming 'partial peripheries' or ad hoc solutions, the present analysis has led to the conclusion that this is due to the interaction of constraints 
operating at different levels of grammar (conversational dynamics, discourse-semantics, syntax and prosody). Specifically:

(a) Imperative clauses are not endowed with assertive illocutionary force but they cannot be considered less than propositions.

(b) Based on the distinction between Type I and Type II root phenomena (where the former type can only occur in CG-active propositions) and assuming a compositional approach to conversational dynamics, imperatives qualify as non-CG-active propositions. As such, they have no update potential in the CG (though they can have access into the CG repository) but, rather, they affect the interlocutor's To-Do-LiST;

(c) Imperative clauses are dominated by a super-ordinate Speech Act Phrase, which includes the SPEAKER and the ADDRESSEE as co-arguments;

(d) Given the lack of update potential, the interpretation of imperatives is not connected with assertive illocutionary Force, but with a Modality projection in the IP-split domain, which is activated by an Agree relation with the [+DIR] feature in the C-domain;

(e) Given the interface avoidance strategy of prosodic clashes, the unacceptability/strong marginality of G-Topics in the left periphery of imperative clauses can be comprehensively accounted for;

(f) Assuming that agreement is as a type of 'allocutive agreement' in C, the general block on fronted Corrective Foci and Contrastive Topics in languages like English can be independently attributed to an intervention effect: syntax blocks the movement of discourserelated categories that interfere with the allocutive probe in Fin ${ }^{\circ}$ since they create crossing chains and these are banned when triggered by different heads.

\section{References}

AbOH, E. O., Hartmann K., Zimmermann M. eds. 2007. Focus Strategies in African Languages. The Interaction of Focus and Grammar in Niger-Congo and Afro-Asiatic. Berlin: Mouton de Gruyter.

Adger, D. \& Svenonius P. 2011. Features in Minimalist syntax. The Oxford handbook of minimalist syntax. ed. C. Boeckx, 27-51. Oxford: Oxford University Press.

ÂMBAR, M. 1999. Aspects of the syntax of focus in Portuguese. The grammar of focus. eds. G. Rebuschi \& M. Tuller, 23-53. Amsterdam \& Philadelphia: John Benjamins. 
BAAYen, R. H. 2008. Analyzing Linguistic Data. A Practical Introduction to Statistics using $R$. Cambridge: Cambridge University Press.

Beukema, F. \& CoOpmans P. 1989. A Government-Binding perspective on the imperative in English. Journal of Linguistics 25: 417-436.

BeAVER, D. \& Clark B. 2008. Sense and sensitivity: How focus determines meaning. Oxford: Blackwell.

BiAnCHI, V. 2013. On Focus movement in Italian. Information Structure and Agreement. eds. V. Camacho-Taboada, Á. L. Jiménez-Fernández, J. Martín-González \& M. ReyesTejedor, 194-215. Amsterdam \& Philadelphia: John Benjamins.

BiAnCHI, V. 2015. Focus Fronting and the syntax-semantics interface. Beyond Functional sequence. The Cartography of Syntactic Structures 10. ed. U. Shlonsky, 60-712. Oxford: Oxford University Press.

BIANCHI, V. \& BocCI G. 2012. Should I stay or should I go? Optional Focus movement in Italian, ed. C. Pinon, Empirical Issues in Syntax and Semantics 9, 1-16. Paris: EISS.

BiANCHI, V, BocCi G. \& CRUSCHINA S. 2015. Focus Fronting and its implicatures. Romance Languages and Linguistic Theory 2013. eds. E. Aboh, J. Schaeffer \& P. Sleeman, 3-20. Amsterdam \& Philadelphia: John Benjamins.

BIANCHI, V. \& FRASCARELLI M. 2010. Is topic a root phenomenon? Iberia 2:43-88.

Bianchi, V. \& Frascarelli M. 2012. How to be rooted in a context. Paper presented at the $35^{\text {th }}$ GLOW Colloquium, University of Postdam.

BIRNER, B. 1995. Pragmatic constraints on the verb in English inversion. Lingua 97.4:233256.

BRUNETTI, L. 2009. On the pragmatics of post-focal material in Italian (left peripheral focus looked from the other side. Les linguistiques du détachement. Actes du Colloque de Nancy, Juin 7-9, 2006. eds. D. Apothéloz, B. Combettes \& F. Neveu, 151-162. Berne: Peter Lang.

BÜRING, D. 1999. Topic. Focus, linguistic cognitive and computational perspectives. eds. P. Bosch \& R. van der Sandt, 142-165. Cambridge: Cambridge University Press.

BÜRING, D. 2003. On D-trees, beans, and B-Accents. Linguistics and Philosophy 26:511-545.

CAmacho-TABoada, V. \& Á. L. JimÉnez-Fernández. 2014. Focus Fronting and Root Phenomena in Spanish and English. Language Use and Linguistic Structure. eds. J. Emonds \& M. Janebová, 41-60. Olomouc: Palacky University. 
CARDinAletti, A. 2002. Against optional and zero clitics. Right dislocation vs. marginalization. Studia Linguistica 56:29-57.

CARdinaletti, A. 2009. On a (wh-)moved Topic in Italian, compared to Germanic. Advances in Comparative Germanic Syntax. eds. A. Alexiadou, J. Hankmaer, T. McFadden, J. Nuger \& F. Schaeffer, 3-40. Amsterdam \& Philadelphia: John Benjamins.

CHAFE, W. 1976. Givenness, contrastiveness, definiteness, subjects, topics, and point of view. Subject and Topic. ed. Ch. N. Li, 25-55. New York: Academic Press.

CHIERCHIA, G. 1985. Formal semantics and the grammar of predication. Linguistic Inquiry $16: 417-443$.

Chierchia, G. \& S. MCConnell-Ginet. 1990. Meaning and Grammar: An Introduction to Semantics. Cambridge, MA: MIT Press.

Chomsky, N. 2008. On phases. Issues in Linguistic Theory. Essays in Honor of Jean-Roger Vergnaud. eds. R. Freidin, C. Peregrin Otero \& M. L. Zubizarreta, 133-166. Cambridge, MA: MIT Press.

CinQue, G. 1990. Types of A'-Dependencies. Cambridge, MA: MIT Press.

CORMANY, E. 2013. A preference analysis of imperatives connecting syntax, semantics and pragmatics. University of Cornell: Ph.D dissertation.

CRUSCHINA, S. 2011. Fronting, dislocation and the syntactic role of discourse-related features. Linguistic Variation 11:1-34.

DAYAL, V. \& GRIMSHAW J. 2009. Subordination at the interface. Unpublished manuscript, Rutgers University.

DownING, B. 1969. Vocatives and third-person imperatives in English. Papers in Linguistics 1:570-592.

EMONDS, J. 1970. Root and Structure-Preserving Transformations. MIT: Ph.D. dissertation.

EMONDS, J. 1976. A transformational approach to English syntax: Root, structure-preserving, and local transformations. New York: Academic Press.

EMONDS, J. 2004. Unspecified categories as the key to root constructions. Peripheries: Syntactic Edges and their Effects. eds. D. Adger, C. de Cat \& G. Tsoulas, 75-120. Dordrecht: Kluwer.

Esteban-Vilaplana, E. \& Prieto, P. 2010. Castilian Spanish intonation. Transcription of Intonation of the Spanish Language. eds. Pilar Prieto \& P. Roseano, 17-48. München: Lincom Europa. 
EvANS N. 2007. Insubordination and its uses. Finiteness: Theoretical and Empirical Foundations. ed. I. Nikolaeva, 366-431. Oxford: Oxford University Press.

FARKAS, D. F. \& BRUCE, K. B. 2010. On reacting to assertions and polar questions. Journal of Semantics 27:81-118.

Frascarelli, M. 2000. The Syntax-Phonology Interface in Focus and Topic Constructions in Italian. Studies in Natural Language and Linguistic Theory 50. Dordrecht: Kluwer.

Frascarelli, M. 2007. Subjects, Topics and the Interpretation of Referential pro. An interface approach to the linking of (null) pronouns. Natural Language and Linguistic Theory, 25:691-734.

Frascarelli, M. 2010a. Narrow Focus, Clefting and Predicate Inversion. Lingua 120.9:2121-2147.

FRASCARELLI, M. 2010b. Intonation, Information Structure and the Derivation of Inverse VO Languages: An Interface Analysis of Tagalog and Malagasy. Austronesian and Theoretical Linguistics. eds. R. Mercado, E. Potsdam \& L. deMena Travis, 81-101. Amsterdam \& Philadelphia: John Benjamins.

Frascarelli, M. 2017. Dislocations and Framings. Manual of Romance Morphosyntax and Syntax. eds. E. Stark \& A. Dufter, 472-510. Berlin: Mouton de Gruyter.

FRASCARELLI, M. 2018. The interpretation of pro in consistent and partial NS languages: A comparative interface analysis. Null-Subjects in Generative Grammar. A synchronic and diachronic perspective. eds. F. Cognola \& J. Casalicchio, 211-239, Part IIB, Ch. 9. Oxford University Press, Oxford/New York.

Frascarelli, M. 2019. Topics, Conversational dynamics and the Root/Non-root distinction: Adverbial clauses at the Discourse-syntax Interface. Architecture of Topics. eds. V. Molnár, V. Egerland \& S. Winkler, 139-170. Berlin: Mouton De Gruyter.

Frascarelli, M. \& G. CARElla 2019. Topic chains and the interpretation of null subjects: The acquisition of discourse-related strategies in Italian. The Linguistic Review 36.4:637674.

Frascarelli, M. \& HinterhölzL, R. 2007. Types of topics in German and Italian. On Information Structure, Meaning and Form. eds. K. Schwabe \& S. Winkler, 87-116. Amsterdam \& Philadelphia, John Benjamins. 
FrASCARELLI, M. \& HinterhÖlzL, R. 2016. German scrambling meets Italian RightDislocation. Paper presented at the 42th Incontro di Grammatica Generativa, University of Salento.

FrAsCARELLI, M. \& JiMÉNEZ-FERNÁNDEZ, Á. L. 2019. Understanding partiality in pro-drop languages: An information-structure approach. Syntax (Special Issue on Information Structure) 22.2-3:162-198.

Frascarelli, M. \& Ramaglia, F. 2013. Phasing contrast at the interfaces. Information Structure and Agreement. eds. V. Camacho-Taboada, Á. L. Jiménez-Fernández, J. Martín-González \& M. Reyes-Tejedor, 55-82. Amsterdam \& Philadelphia: John Benjamins.

GÄRTNER, H-M. 2002. On the force of V-2 declaratives, Theoretical Linguistics 28:33-42.

Gianollo, C. 2016. The Latin System of Negation at the Syntax-Semantics Interface. Rivista di Grammatica Generativa 38:115-135.

Gili-Fivela, B, Avesani, C., Barone, M., Bocci, G., Crocco, C., D’Imperio, M., Giordano, R., Marotta, G., SAVio, M. \& Sorianello, P. 2015. Varieties of Italian and their intonational phonology. Intonational Variation in Romance. eds. S. Frota \& P. Prieto, 140-197. Oxford: Oxford University Press.

Gregory, M., \& Michaelis, L. 2001. Topicalization and Left Dislocation: A functional opposition revisited. Journal of Pragmatics 33:1665-1706.

HAEgEman, L. 2002. Anchoring to Speaker, adverbial clauses and the structure of CP. Georgetown University Working Papers in Theoretical Linguistics 2:117-180.

HAEgeman, L. 2004. Topicalization, CLLD and the left periphery. ZAS Papers in Linguistics 35: Proceedings of the Dislocated Elements Workshop. eds. C. Maienborn, W. Frey \& B. Shaer, 157-192. Berlin.

HAEgEMAN, L. 2006. Conditionals, factives and the left periphery. Lingua 116:1651-1669.

HAEGEMAN, L. 2010. The internal syntax of adverbial clauses. Lingua 120:628-648.

HAEgEMAn, L. 2012. Adverbial clauses, main clause phenomena, and the composition of the left periphery. Oxford: Oxford University Press.

HAEGEMAN, L. 2014. West Flemish verb-based discourse markers and the articulation of the Speech Act Layer. Studia Linguistica 68.1:116-139.

Haegeman, L. \& Hill, V. 2013. The syntactization of discourse. Syntax and its Limits. eds. R. Folli, C. Sevdali \& R. Truswell, 370-390. Oxford: Oxford University Press. 
Haegeman, L. \& MiYagawa, S. 2016. The syntax of participants. Keynote address GLOW workshop. https://www.uni-goettingen.de/en/510390.html.

HAEgEMAN, L. \& ÜRÄGDI, B. 2010. Referential CPs and DPs: An operator movement account. Theoretical Linguistics 36.2-3:111-152.

HAN, C.-H. 2000. The Structure and Interpretation of Imperatives: Mood and Force in Universal Grammar. Garland, Outstanding Dissertations in Linguistics.

HAN, C.-H. 2001. Force, Negation and Imperatives. The Linguistic Review 18:289-325.

HARTMANN, K. 2001. Right node raising and gapping. Amsterdam \& Philadelphia: John Benjamins.

HeIM, I. 1982. The Semantics of Definite and Indefinite Noun Phrases. University of Massachusetts at Amherst, Ph.D. dissertation.

Hengeveld, K. \& MackenZIE, L. 2008. Functional Discourse Grammar. Oxford: Oxford University Press.

Heycock, C. 2006. Embedded Root Phenomena. The Blackwell Companion to Syntax. eds. M. Everaert \& H. van Riemsdijk, 174-209. Oxford: Basic Blackwell.

HILL, V. 2007a. Romanian adverbs and the pragmatic field. The Linguistic Review 24:61-86.

HILL, V. 2007b. Vocatives and the pragmatics-syntax interface. Lingua 117:2077-2105.

HILL, V. 2008. Pragmatics markers as syntactic heads: a case study from Romanian. Syntaxfest Cyprus Conference. eds. K. Grohmann \& P. Panagiotidis, 237-265. Newcastle-upon-Tyne: Cambridge University Scholars Press.

HOOPER, J. \& THOMPSON, S. 1973. On the applicability of root transformations. Linguistic Inquiry 4:465-497.

Huddleston, R. \& Pullum, G. K. 2002. The Cambridge Grammar of the English Language. Cambridge: Cambridge University Press.

JENSEN, B. 2007. In favour of a truncated imperative clause structure: evidence from adverbs. Working Papers in Scandinavian Syntax 80:163-185.

JiMÉNEZ-FERNÁNDEZ, Á. L. 2011. On the Order of Multiple Topics and Discourse-feature Inheritance. Dilbilim Araştırmaları (Journal of Linguistic Research) 1:5-32.

JIMÉNEZ-FERNÁNDEZ, Á. L. 2015a. When focus goes wild: An empirical study of two syntactic positions for information Focus. Linguistics Beyond and Within 1:119-133. 
JiMÉNEZ-FERNÁNDEZ, Á. L. 2015b. Towards a typology of focus: Subject position and microvariation at the discourse-syntax interface. Ampersand: An International Journal of General and Applied Linguistics 2:49-60.

JiMÉNEZ-FERNÁNDEZ, Á. L. 2016. When discourse met null subjects. Borealis: An International Journal of Hispanic Linguistics 5.2:173-189.

JiMÉNEZ-FERNÁNDEZ, Á. L. 2018. Negative Preposing: Intervention and parametric variation in complement clauses. Atlantis: Journal of the Spanish Association for Anglo-American Studies 40.1:11-37.

JIMÉNEZ-FERNÁNDEZ, Á. L. 2020. Syntax-information structure interactions in the sentential, verbal and nominal peripheries. Newcastle: Cambridge Scholars Publishing.

JiMÉnEZ-FernÁNDEZ, Á. L. \& MiYagaWA, S. 2014. A feature-inheritance approach to root phenomena and parametric variation. Lingua 145:276-302.

KAUFMANN M. 2012. Interpreting imperatives. Dordrecht: Springer (Studies in Linguistics and Philosophy 88).

KISS, K. É. 1998. Identificational focus versus information focus. Language 74:245-273.

KoOpman, H. 2007 Topics in imperatives. Imperative Clauses in Generative Grammar. ed. W. van der Wurff, 153-180. Amsterdam \& Philadelphia: John Benjamins.

Kratzer, A. \& SelKirK, E. 2009. Distinguishing contrastive, new and given information. Paper presented at the Workshop on Prosody and Meaning, Barcelona.

KRIFKA, M. 1992. The semantics and pragmatics of polarity items. Linguistic Analysis 25:209-257.

KrIFKA, M. 2001. Quantifying into question acts. Natural Language Semantics 9:1-40.

KRIFKA, M. 2007. Basic Notions of Information Structure. eds. C. Féry \& M. Krifka, Interdisciplinary Studies on Information Structure, 13-55. ISIS, Universitätverlag Potsdam.

KRIFKA, M. 2015. Bias in Commitment Space Semantics: Declarative questions, negated questions, and question tags. Proceedings of SALT 25:328-345.

KunO, S. 1987. Functional Syntax. Chicago: University of Chicago Press.

KunO, S. \& KabURAKI, E. 1977. Emphaty and Syntax. Linguistic Inquiry. 8:627-672.

LAUER, S. 2013. Towards a dynamic Pragmatics. Stanford University, PhD dissertation.

LAEnZlinger, C. 1998. Comparative studies in word order variation. Amsterdam \& Philadelphia: John Benjamins. 
LeONetTI, M. \& EscAndell, V. 2009. Fronting and verum-focus in Spanish. Focus and background in Romance languages. eds. A. Dufter \& J. Daniel, 155-204. Amsterdam \& Philadelphia: John Benjamins.

LikerT, R. 1932. A technique for the measurement of attitudes. Archives of Psychology $22: 140-155$.

VAN LEUSEN, N. 2004. Incompatibility in context: a diagnosis of correction. Journal of Semantics 21:415-442.

MAKI, H. KAISER, L. \& OCHI, M. 1999. Embedded topicalization in English and Japanese. Lingua 109:1-14.

MCCAWley A. 1977. What is the 'Emphatic Root Transformation' Phenomenon?' Chicago Linguistic Society 13: 384-400.

MEINUNGER, A. 2004. Verb position, verbal mood and the anchoring (potential) of sentences. The Syntax and Semantics of the Left Periphery. eds. H. Lohnstein \& S. Trissler, 313341. Berlin: Mouton de Gruyter.

Menza, S. 2006. Il Paraverbo. L'interiezione come Sottoclasse del Verbo. Alessandria: Edizioni dell'Orso.

MiYagawA S. 2012. Agreements that occur mainly in the main clause. Main Clause Phenomena. eds. L. Aelbrecht, L. Haegeman \& R. Nye, 79-112. Amsterdam \& Philadelphia: John Benjamins.

MOLNÁR, V. 2006. On different kinds of contrast. The architecture of focus. eds. V. Molnár \& S. Winkler, 197-233. Berlin: Mouton de Gruyter.

NeEleman, A. \& ReInHART, T. 1998. Scrambling at the PF interface. The Projections of Arguments: Lexical and Compositional Factors. eds. W. Geuder \& M. Butts. Stanford: CSLI

NeSPOR, M. \& VogeL, I. 1979. Clash avoidance in Italian. Linguistic Inquiry 10:467-482.

OIKONOMOU, D. 2016. Imperatives are existential modals: deriving the strong reading as an implicature. Proceedings of SALT 26:1043-1062.

PIERREHUMBERT, J. B. 1980. The phonology and phonetics of English intonation. MIT: Ph.D dissertation.

Pierrehumbert, J. B. \& Hirschberg, J. 1990. The Meaning of Intonational Contours in the Interpretation of Discourse. Intentions in Communication. eds. P. R. Cohen, J. Morgan \& M. E. Pollack, 271-311. Cambridge MA: MIT Press. 
Poletto, C. \& Zanuttini, R. 2003. Making imperatives: Evidence from Central Rhaetoromance. The syntax of Italian dialects. ed. C. Tortora, 175-206. Oxford: Oxford University Press.

Portner, P. \& YABUShitA, K. 1998. The semantics and pragmatics of Topic phrases. Linguistics and Philosophy 21:117-157.

Portner, P., PAK, M. \& ZANUTtini, R. 2019. The speaker-addressee relation at the syntaxsemantics interface. Language 95.1:1-36.

PoTSDAM, E. 1998. Syntactic Issues in the English Imperative. New York: Garland.

PRIETO, P. 2011. Prosodic effects on phrasing: Clash avoidance in Catalan. Lingua 121:19231933.

PRINCE, E. 1981. Toward a taxonomy of given-new information. Radical Pragmatics. ed. P. Cole, 223-254. New York: Academic Press.

PRINCE, E. 1998. On the limits of syntax, with reference to Left-Dislocation and Topicalization. Syntax and Semantics 29: The Limits of Syntax. eds. P. Culicover \& L. McNally, 281-302. New York: Academic Press.

Puglielli, A. \& Frascarelli, M. 2009. Position, Function and Interpretation of Topics in Somali. Information Structure and Its Interfaces. ed. L. Mereu, 325-348. Berlin: Mouton de Gruyter.

REINHART, T. 1982. Pragmatics and Linguistics: An Analysis of Sentence Topics. Philosophica 27:53-94.

REIS, M. 1999. On sentence types in German: An enquiry into the relationship between grammar and pragmatics. IJGLSA 2.4:195-236.

RICHARDS, N. W. 1999. Cyclicity and the ordering of multiple specifiers. Working Minimalism. eds. S. Epstein \& N. Hornstein, 127-158. Cambridge, MA: MIT Press.

Rivero, M. L. 1994. Clause structure and V-movement in the languages of the Balkans. Natural Language and Linguistic Theory 12:62-120.

Rivero, M. L. \& TerZI, A. 1995. Imperatives, V-movement and logical mood. Journal of linguistics 31:301-332.

RizzI, L. 1997. The fine structure of the left periphery. Elements of grammar. Handbook in Generative Syntax. ed. L. Haegeman, 281-337. Dordrecht: Kluwer. 
RIZZI, L. 2004. Locality and the left periphery. Structures and beyond: The Cartography of syntactic structures, vol. 3. ed. A. Belletti, 223-251. Oxford \& New York: Oxford University Press.

RIzZI, L. 2006. On the Form of Chains: Criterial Positions and ECP Effects. Wh-Movement: Moving on. ed. L. Cheng \& N. Corver, 97-133. Cambridge, MA: MIT Press.

RizZI, L. 2007. On Some Properties of Criterial Freezing. CISCL Working Papers on Language and Cognition 1:145-158.

RIZZI, L. 2018. Intervention effects in grammar and language acquisition. Probus 30.2:339367.

RoBerts, C. 2003.Uniqueness in Definite Noun Phrases. Linguistics and Philosophy 26, 287350.

RoberTs, C. 2004. Context in dynamic interpretation. Handbook of Pragmatics. eds. Laurence R. Horn \& Gregory L. Ward, 197-220. London: Basil Blackwell.

RoBerTs, C. 2018. Speech acts in discourse context. New Work on Speech Acts. eds. D. Fogal, D. Harris \& M. Moss, 317-359. Oxford: Oxford University Press.

Roотн, M. 1992. A theory of focus interpretation. Natural Language Semantics 1:75-116.

Ross J. R. 1970. On Declarative Sentences. Readings in English Transformational Grammar. eds. R. A. Jacobs \& P. S. Rosenbaum, 222-272. Washington: Georgetown University Press.

SAG, I. A. 1980. Deletion and logical form. New York: Garland.

SCHWAGER M. 2006. Interpreting imperatives. Goethe Universität zu Frankfurt am Main: Ph.D. dissertation.

SCHWARZSCHILD, R. 1999. GIVENnes, AvoidF and other constraints on the placement of accent. Natural Language Semantics 7:141-177.

Sigurdsson, H. Á. 2011. Conditions on Argument drop. Linguistic Inquiry 42:267-304.

Sigurdsson, H. 2016. The Split T Analysis. Finiteness Matters. ed. K. M. Eide, 79-92. Amsterdam \& Philadelphia: John Benjamins.

SIMONS, M. 2007. Observations on embedding verbs, evidentiality, and presupposition. Lingua 117.6:1034-1056.

SpEAS, M. J. 2000. Evidentiality, Logophoricity and the Syntactic Representation of Pragmatic Features. Lingua 14:255-276. 
Speas, M. J. \& CAROL, T. 2003. Configurational Properties of Point of View Roles. Asymmetry in Grammar. ed. A. M. Di Sciullo, 315-344. Amsterdam \& Philadelphia: John Benjamins.

SzABOLCSI, A. 2005. Strong vs. weak islands. The Blackwell companion to syntax, vol. IV. eds. M. Everaert \& H. Van Riemsdijk, 479-532. Oxford-New York: Wiley-Blackwell.

TAKAhashi, S. \& FoX, D. 2005. MaxElide and the re-binding problem. Proceedings of Semantics and Linguistic Theory 15 (SALT 15). eds. E. Georgala \& J. Howell, 223-240. Ithaca, New York: CLC Publications.

VAllduví, E. \& VilkunA, M.1998. On rheme and contrast. The limits of syntax. eds. P. W. Culicover \& L. McNally 79-108. San Diego: Academic Press.

VAN GERLDEREN, E. 2013. Null Subjects in Old English. Linguistic Inquiry 44:271-285.

Verstraete, J.-C. 2005. Two types of coordination in clause combining. Lingua:115, 611626.

WARD, G., Birner, B. J. \& KAISER, E. 2017. Pragmatics and Information Structure. The Oxford Handbook of Pragmatics. (Part V Interfaces). ed. Y. Huang, 632-676. Oxford: Oxford University Press.

WATANABE, A. 1993. Larsonian CP recursion, factive complements, and selection. NELS 23.2:523-37.

Wiklund, A. L., BentZen, K., HrafnBjargarson, G. H. \& HróARsdótTiR, P. 2009. On the distribution and illocution of V2 in Scandinavian that-clauses. Lingua 119:1914-1938.

ZANUTTINI, R. 1996. On the relevance of tense for sentential negation. Parameters and functional heads: essays in comparative syntax. eds. A. Belletti \& L. Rizzi, 181-207. New York: Oxford University Press.

ZANUTTINI, R. 1997. Negation and clausal structure. Oxford: Oxford University Press.

ZANUTTINI, R. 2008. Encoding the addressee in the syntax: evidence from English imperative subjects. Natural Language and Linguistic Theory 26:185-218.

Zanuttini, R., PAK, M. \& Portner, P. 2012. A syntactic analysis of interpretive restrictions on imperatives, permissives and exhortative subjects. Natural Language and Linguistic Theory 30:1231-1274.

ZANUtTini, R. \& PORTneR, P. 2003. Exclamative clauses: At the syntax- semantics interface. Language 79:39-81. 
ZanUtTINI, R. 1994. Re-examining Negative Clauses. Paths towards Universal Grammar, Studies in Honor of Richard S. Kayne. eds. G. Cinque, J. Koster, J.-Y. Pollock, L. Rizzi \& R. Zanuttini, 427-451. Georgetown: Georgetown University Press.

ZeIJLstra, H. 2006. The ban on true negative imperatives. Empirical issues in syntax and semantics 6:405-424.

Mara Frascarelli

Department of Foreign Languages, Literature and Culture

University of Roma Tre

Via Ostiense, 236

00146 Rome

Italy

mara.frascarelli@uniroma3.it

Ángel L. Jiménez-Fernández

Departamento de Lengua Inglesa

Universidad de Sevilla

C/ Palos de la Frontera $s / n$

41003 Seville

Spain

ajimfer@us.es 